\title{
Bacterial and Fungal Communities Are Differentially Modified by Melatonin in Agricultural Soils Under Abiotic Stress
}

\author{
Andrew P. Madigan ${ }^{1,2}$, Eleonora Egidi ${ }^{3}$, Frank Bedon ${ }^{1 *}$, Ashley E. Franks ${ }^{2,4}$ \\ and Kim M. Plummer ${ }^{1}$
}

${ }^{1}$ Department of Animal, Plant and Soil Sciences, AgriBio, La Trobe University, Melbourne, VIC, Australia, ${ }^{2}$ Department of Physiology, Anatomy and Microbiology, La Trobe University, Melbourne, VIC, Australia, ${ }^{3}$ Hawkesbury Institute for the Environment, Western Sydney University, Richmond, NSW, Australia, ${ }^{4}$ Centre for Future Landscapes, School of Life Sciences, La Trobe University, Melbourne, VIC, Australia

\section{OPEN ACCESS}

Edited by:

Jonàs Oliva

Universitat de Lleida, Spain

Reviewed by:

Erick Amombo,

University of Chinese Academy of Sciences, China

Yan Xie,

University of Chinese Academy of Sciences, China

Muhammad Azher Nawaz, University of Sargodha,

Pakistan

*Correspondence: Frank Bedon

f.bedon@latrobe.edu.au

Specialty section:

This article was submitted to Terrestrial Microbiology,

a section of the journal

Frontiers in Microbiology

Received: 12 June 2019 Accepted: 28 October 2019 Published: 03 December 2019

Citation:

Madigan AP, Egidi E, Bedon F, Franks AE and Plummer KM (2019) Bacterial and Fungal Communities Are Differentially Modified by Melatonin in Agricultural Soils Under Abiotic Stress.

Front. Microbiol. 10:2616. doi: 10.3389/fmicb.2019.02616
An extensive body of evidence from the last decade has indicated that melatonin enhances plant resistance to a range of biotic and abiotic stressors. This has led to an interest in the application of melatonin in agriculture to reduce negative physiological effects from environmental stresses that affect yield and crop quality. However, there are no reports regarding the effects of melatonin on soil microbial communities under abiotic stress, despite the importance of microbes for plant root health and function. Three agricultural soils associated with different land usage histories (pasture, canola or wheat) were placed under abiotic stress by cadmium (100 or $280 \mathrm{mg} \mathrm{kg}^{-1}$ soil) or salt (4 or $7 \mathrm{~g} \mathrm{~kg}^{-1}$ soil) and treated with melatonin ( 0.2 and $4 \mathrm{mg} \mathrm{kg}^{-1}$ soil). Automated Ribosomal Intergenic Spacer Analysis (ARISA) was used to generate Operational Taxonomic Units (OTU) for microbial community analysis in each soil. Significant differences in richness ( $\alpha$ diversity) and community structures ( $\beta$ diversity) were observed between bacterial and fungal assemblages across all three soils, demonstrating the effect of melatonin on soil microbial communities under abiotic stress. The analysis also indicated that the microbial response to melatonin is governed by the type of soil and history. The effects of melatonin on soil microbes need to be regarded in potential future agricultural applications.

Keywords: melatonin, microbial ecology, automated ribosomal intergenic spacer analysis, abiotic stress, salt, cadmium

\section{INTRODUCTION}

Soil microbial communities have an essential role in maintaining ecosystem health. Microbes can exchange nutrients and minerals directly with the plant root systems as well as indirectly benefit plant growth through nutrient cycling of organic matter in soils (Wall and Virginia, 1999; Yao et al., 2000; Kirk et al., 2004; Wahid et al., 2016). The diversity and structure of microbial communities in soils can be altered by various abiotic stresses. Community alterations can have important consequences for ecosystem-level functions provided by soil microbes (Mau et al., 2019; Zhang et al., 2019). Among the various abiotic stresses that pose a significant 
threat to many terrestrial systems, increasing levels of salinity and contaminants due to anthropogenic activities have a prominent role (Badri and Vivanco, 2009; Wood et al., 2016a,b; Geisseler et al., 2017).

Mining, industrial air pollution and phosphorus fertilizer treatments have been responsible for introducing vast quantities of the highly toxic heavy metal cadmium into the environment (Jiao et al., 2012; Khairy et al., 2014; Qadir et al., 2014). In China alone, 743 metric tons of cadmium were released by such anthropogenic activities in a single year (Cheng et al., 2014), causing cadmium to be the most abundant heavy metal contaminant in agricultural soils (Wang et al., 2019). Cadmium is a serious health issue in humans due to its ability to accumulate in edible crops such as rice (Oryza sativa) and soybean (Glycine max) (Franzaring et al., 2019; Wang et al., 2019). Contaminated irrigation water is a common source of cadmium or salt into agricultural soils (Khairy et al., 2014; Qadir et al., 2014; Roberts, 2014; Bencherif et al., 2015; Franzaring et al., 2019). Up to 2 million hectares of agricultural land is negatively impacted by salinization each year globally (Bencherif et al., 2015; Ke et al., 2017). Salt stress can impact ion homeostasis, photosynthetic capacity, and root and shoot dry weight in plants (Zhan et al., 2019).

In microbes, both cadmium toxicity and soil salinization cause a dramatic increase in cellular levels of highly destructive reactive oxygen species (ROS) as well as inhibit the activities of ROS scavenging enzymes (Tanaka et al., 2006; Achard-Joris et al., 2007; Hossain et al., 2012). Soil microbial community structures and activities are altered by cadmium toxicity and salinity (Cáliz et al., 2013; Rath et al., 2016; Wood et al., 2016a,b; Thiem et al., 2018). Such alterations to the soil microbial community have important repercussions in agricultural settings, where microbes (both soil bacteria and fungi) are critical drivers of soil health and agricultural crop productivity (Mau et al., 2019; Zhang et al., 2019). As such, exploring novel avenues to control stress-induced shifts in soil microbial community composition and functionality could be a key to unfolding agricultural constraints and achieve better agricultural productivities and sustainable development in the future.

Melatonin (N-acetly-5-methoxytryptamine) is an indoleamine (secondary metabolite) produced by all cellular organisms (Hardeland, 2015; Manchester et al., 2015). In plants, melatonin has been shown to decrease the physiological deleterious effect of various abiotic stresses (Zhang et al., 2015; Nawaz et al., 2016; Sharif et al., 2018; Debnath et al., 2019). Exogenous melatonin application via seed-coatings (Wei et al., 2015), soil treatments (Cui et al., 2017), or foliar sprays (Zhang et al., $2017 \mathrm{a}, \mathrm{b}$ ) have been described to promote growth and protect plants against stressors such as cadmium (Byeon et al., 2015; Li et al., 2016; Gu et al., 2017) and salt (Li et al., 2012; Liang et al., 2015; Jiang et al., 2016). Melatonin can act either as a highly efficient antioxidant, scavenging up to 10 ROS per molecule, or as a signaling molecule regulating enzymes or hormones associated with ROS scavenging (Weeda et al., 2014; Reiter et al., 2015, 2016; Zhang et al., 2015; Hardeland, 2016; Nawaz et al., 2018). Melatonin exposure alters microbiota composition in the gut (Schultz et al., 2006; Chen et al., 2011) and may have antibiotic activity against some microbes (Lucchelli et al., 1997). However, very little is known about the effects of this secondary metabolite on individual microbes or mixed microbial communities in soil, especially under abiotic stress conditions (Tan et al., 2014; Manchester et al., 2015; Paulose et al., 2016). Therefore, the viability of melatonin application to future agricultural practices may be explored by investigating how melatonin influences soil microbial community dynamics.

The aim of this research is to advance our understanding of how chemically stressed soil microbial communities respond to exogenous melatonin, thus enhancing knowledge of potential plant-soil microbe interactions under the presence of this secondary metabolite. We examined the effects of melatonin on microbial community structures in three different agricultural soils which were artificially stressed with cadmium or salt. This study is focused upon answering: How does melatonin affect the $\alpha$ and $\beta$ diversity of soil microbes? How similar are the responses of bacterial and fungal communities to melatonin and/or abiotic stresses? Are microbial community responses to melatonin and/or abiotic stresses similar across the different agricultural soils? We hypothesized that: (1) bacteria would be more responsive to treatments compared to fungi; (2) melatonin would impact microbial community structures in soils (a) unstressed and (b) under abiotically stressed conditions to varying degrees across the three soils; (3) specific OTUs would be particularly responsive under the various conditions. This is the first study to date to report significant responses of microbes to melatonin under abiotic stress in agricultural soils at a community level.

\section{MATERIALS AND METHODS}

\section{Soils Origin, Sampling, and Physiochemical Characteristics}

Three agricultural soils associated with different land uses (pasture and crops) were collected from sites within Victoria, Australia. Prior to sampling in late March and early April 2017, site "P" ( $37^{\circ} 32^{\prime} 28.1^{\prime \prime}$ S, $145^{\circ} 05^{\prime} 42.5^{\prime \prime}$ E) was most recently ( $<3$ months) associated with cattle and sheep Pasture, site "C" $\left(37^{\circ} 45^{\prime} 28.4^{\prime \prime}\right.$ S, $144^{\circ} 14^{\prime} 30.2^{\prime \prime}$ E) was 3 weeks post Canola harvest, and site "W" $\left(37^{\circ} 43^{\prime} 31.1^{\prime \prime} \mathrm{S}, 144^{\circ} 13^{\prime} 14.3^{\prime \prime}\right.$ E) was 3 weeks post-fire blazing of stubble following a Wheat harvest. As the plant species associated with a soil has been shown to be a key factor influencing the bacterial community structure within the rhizosphere (Burns et al., 2015), it was expected that selecting these soils would provide the most diverse range of soil microbes for the current study.

At each site, approximately $4 \mathrm{~kg}$ topsoil was sampled $(10 \mathrm{~cm}$ deep $\times 0.5 \mathrm{~m}$ width $\times 0.5$ length) from each of four plots spaced $3 \mathrm{~m}$ apart. Air temperature ranged approximately $28^{\circ} \mathrm{C} / 12^{\circ} \mathrm{C}$ day/night at the time of sampling and soils were dry for at least a week when sampled in the field. Soil samples were subsequently air dried overnight and sieved to remove particles larger than $2 \mathrm{~mm}$. A single soil sample was generated for each site by pooling all four collected soils from the subsite plots (Aye et al., 2016; Butterly et al., 2016). The collected 
TABLE 1 | Physical and chemical characteristics of the three agricultural soils used in this study. Four topsoil samples $(0-10 \mathrm{~cm})$ were collected at each site and composited prior to analysis.

\begin{tabular}{|c|c|c|c|}
\hline Site & $\mathbf{P}$ & C & $\mathbf{W}$ \\
\hline Available potassium (mg kg-1 soil) & 640 & 140 & 170 \\
\hline $\mathrm{pH}\left(1: 5 \mathrm{CaCl}_{2}\right)$ & 6.1 & 4.9 & 4.7 \\
\hline Organic carbon (\%) & 4.6 & 3 & 2.8 \\
\hline Nitrate N (mg kg ${ }^{-1}$ soil) & 160 & 57 & 34 \\
\hline Ammonium $\mathrm{N}$ (mg kg ${ }^{-1}$ soil) & 2.5 & 8.9 & 8.8 \\
\hline Phosphorus (Colwell) (mg kg ${ }^{-1}$ soil) & 160 & 41 & 32 \\
\hline Phosphorus buffer index & 32 & 71 & 83 \\
\hline Calcium [cmol(+) kg-1 soil] & 12 & 5.1 & 4.7 \\
\hline CEC $\left[\mathrm{cmol}(+) \mathrm{kg}^{-1}\right.$ soil $]$ & 15.7 & 7.94 & 8.56 \\
\hline EC (1:5 water) $\left(\mathrm{dS} \mathrm{m}^{-1}\right)$ & 0.37 & 0.24 & 0.18 \\
\hline Chloride (mg kg-1 soil) & 37 & 67 & 76 \\
\hline Moisture (\%) & 14 & 6 & 5.2 \\
\hline Water holding capacity (\%) & 38.4 & 24.6 & 21.1 \\
\hline Sand (\%) & 75.2 & 53.9 & 52.4 \\
\hline Silt (\%) & 23.6 & 29.9 & 28.8 \\
\hline Clay (\%) & 1.2 & 16.2 & 18.8 \\
\hline Iron (mg kg-1 soil) & 5,400 & 16,000 & 21,000 \\
\hline Zinc (mg kg-1 soil) & 23 & 7.2 & 9.3 \\
\hline Cadmium (mg kg ${ }^{-1}$ soil) & 0.24 & 0.13 & 0.2 \\
\hline Chromium (mg kg ${ }^{-1}$ soil) & 11 & 17 & 32 \\
\hline Nickel (mg kg-1 soil) & 4 & 4.7 & 22 \\
\hline Lead (mg kg-1 soil) & 7.7 & 9.4 & 16 \\
\hline
\end{tabular}

CEC, cation exchange capacity; EC, electrical conductivity; Soil $P$, recently ( $<3$ months) associated with cattle and sheep pasture; Soil C, sampled 3 weeks post canola harvest; Soil W, sampled 3 weeks post-fire blazing following wheat harvest.

stock soils were separately stored at ambient room temperature $\left(21^{\circ} \mathrm{C}\right)$ in airtight plastic containers for 4 months, followed by subsampling (representing the first sampling timepoint; labeled as "T0" in the analysis) for immediate treatments as described below. During this first soil subsampling process stock soils were thoroughly aerated. The stock soils were then stored at ambient room temperature $\left(21^{\circ} \mathrm{C}\right)$ in airtight plastic containers for a further 4 weeks and subsampled for immediate treatments (representing the second sampling timepoint; labeled as "T1" in the analysis). It was expected that this aging regime would change the initial microbial populations and potentially shift selection pressures among the populations (Kelly et al., 1999; Castro et al., 2010; Heijboer et al., 2018; Reese et al., 2018). The four-week lag between $\mathrm{T} 0$ and $\mathrm{T} 1$ sampling timepoints was introduced to reduce any effects on soil microbial community structures within soils caused by the disturbance of soils associated with subsampling. Physicochemical analyses of untreated soils were conducted by Nutrient Advantage (Melbourne, Australia) (Table 1). Electrical conductivities (EC) of untreated and salt-treated $(\mathrm{NaCl})$ soils were determined using 1:5 soil:water as per $\mathrm{He}$ et al. (2012) (Table 2).

\section{Soils Treatment With Abiotic Stress (Cadmium or Salt) and Melatonin}

The responses of soil microbial communities to exogenous melatonin application were investigated with and without cadmium and salt as separately applied stressors (all chemicals from Sigma Aldrich Pty. Ltd., Australia). Five grams of sieved topsoil was transferred to a sterile $50 \mathrm{ml}$ Falcon tube and exposed to various treatment combinations. At sampling timepoint T0, treatments were composed of high or low melatonin (4 or $0.2 \mathrm{mg} \mathrm{kg}{ }^{-1}$ soil, respectively) and/or high or low cadmium (cadmium chloride hemipentahydrate) (280 or $100 \mathrm{mg} \mathrm{kg}^{-1}$ soil, respectively). At sampling timepoint $\mathrm{T} 1$, dry (untreated) soils were treated with a solution composed of melatonin (4 or $0.2 \mathrm{mg} \mathrm{kg}^{-1}$ soil) and/ or high or low salt $(\mathrm{NaCl})$ stressor ( 7 or $4 \mathrm{~g} \mathrm{~kg}^{-1}$ soil, respectively). Controls involved dilute ethanol replacing melatonin (see below) and/or sterile Milli-Q water replacing cadmium. These concentrations were selected to be within the range of those reported to induce effects on soil microbial activities in previous studies for cadmium (Cáliz et al., 2013; Wood et al., 2016a,b) and salt (Rath et al., 2016). Based upon preliminary studies, soils were treated to $80-90 \%$ field capacity, to ensure all soils were sufficiently exposed to stressor and melatonin. Soils without the addition of a stressor acted as a control. Treatments and controls were conducted in quadruplicates. Samples were incubated in sterile $50 \mathrm{ml}$ falcon tubes covered with loosely fitted lids to enable gas exchange at room temperature $\left(21^{\circ} \mathrm{C}\right)$ in darkness for 10 days. Four untreated samples (i.e., no water added) replicates per soil were also collected on Day 0 to provide a representation of the baseline communities prior to treatments.

Melatonin was initially dissolved in $99.9 \%$ ethanol to $200 \mathrm{mM}$ and diluted to the required concentrations with sterile Milli-Q water. All treatments and controls contained a standardized amount of ethanol ( $100 \mu \mathrm{l}$ of $0.43 \%$ ethanol per $5 \mathrm{~g}$ soil). Due to differing water holding capacities for each soil, this equated to a final dilute ethanol concentration of $0.044,0.052$, and $0.06 \% \mathrm{v} / \mathrm{v}$ in treatments within soils $\mathrm{P}, \mathrm{C}$, and $\mathrm{W}$ respectively. Similarly, high melatonin (4 mg kg-1 soil) treatments corresponded to equivalent concentrations of 88.3, 103.1, and $120.3 \mu \mathrm{M}$ melatonin, respectively, while low melatonin (0.2 $\mathrm{mg} \mathrm{kg}^{-1}$ soil) corresponded to equivalent concentrations of $4.4,5.2$, and $6.0 \mu \mathrm{M}$ melatonin respectively. Control treatments were composed of dilute ethanol replacing melatonin and sterile Milli-Q water replacing cadmium (sampling timepoint T0) or $\mathrm{NaCl}$ (sampling timepoint $\mathrm{T} 1$ ).

\section{DNA Extraction and Amplification for Automated Ribosomal Intergenic Spacer Analysis}

Automated Ribosomal Intergenic Spacer Analysis (ARISA) is a molecular technique used to characterize the microbial diversity within various environments, including bulk soil and the rhizosphere (Sørensen et al., 2009; Rincon-Florez et al., 2013). This technique fingerprints fungal and bacterial communities based upon the length heterogeneity of the intergenic spacer region between the ribosomal ribonucleic acid (rRNA) genes for bacteria (16S and 23S) and/or fungi (18S and 28S) (Kirk et al., 2004). ARISA provided a valuable estimate of both species richness and relative abundances, allowing a comparison of $\alpha$ and $\beta$ diversity both across various sites and between samples exposed to different treatments (Zancarini et al., 2012).

Total soil DNA was extracted from $0.3 \mathrm{~g}$ of soil subsamples using PowerSoil ${ }^{\circledR}$ DNA Isolation Kit (MoBio Laboratories Inc., California, USA) according to manufacturer's instructions. For 
TABLE 2 | Electrical conductivity (milli Siemens/centimeter) (mS/cm) in soils P, C and W treated with high (7 $\mathrm{g} \mathrm{kg}^{-1} \mathrm{soil}$ and low (4 $\mathrm{g} \mathrm{kg}{ }^{-1}$ soil) salt (NaCl).

\begin{tabular}{|c|c|c|c|c|c|c|c|c|c|}
\hline \multicolumn{10}{|c|}{ EC 1:5 (mS/cm) } \\
\hline & \multicolumn{3}{|c|}{ Soil P } & \multicolumn{3}{|c|}{ Soil C } & \multicolumn{3}{|c|}{ Soil W } \\
\hline & $7 \mathrm{~g} \mathrm{~kg}^{-1}$ & $4 \mathrm{~g} \mathrm{~kg}^{-1}$ & Control & $7 \mathrm{~g} \mathrm{~kg}^{-1}$ & $4 \mathrm{~g} \mathrm{~kg}^{-1}$ & Control & $7 \mathrm{~g} \mathrm{~kg}^{-1}$ & $4 \mathrm{~g} \mathrm{~kg}^{-1}$ & Control \\
\hline Rep 1 & 2.6 & 1.72 & 0.706 & 1.97 & 1.015 & 0.091 & 1.934 & 1.148 & 0.101 \\
\hline Rep 2 & 2.545 & 1.708 & 0.678 & 1.943 & 1.083 & 0.132 & 1.954 & 1.089 & 0.093 \\
\hline Rep 3 & 2.502 & 1.8 & 0.681 & 1.829 & 1.084 & 0.138 & 1.983 & 1.065 & 0.102 \\
\hline Mean & 2.549 & 1.743 & 0.688 & 1.914 & 1.061 & 0.120 & 1.957 & 1.101 & 0.099 \\
\hline SE & 0.028 & 0.029 & 0.009 & 0.043 & 0.023 & 0.015 & 0.014 & 0.025 & 0.003 \\
\hline
\end{tabular}

Control treatments consist of sterile Milli-Q water replacing salt solutions. All treatments and controls within the same soil were significantly different ( $p<0.05)$ from each other as determined by one-way ANOVA. Salinity levels as measured by electrical conductivity [EC (1:5 soil:water)]. SE, standard error.

the fungal community analysis, the internal transcribed spacer regions 1 and 2 (ITS 1 and 2) were amplified using fungal primers ITS-1F and ITS-4 (Blaalid et al., 2013). A $20 \mu \mathrm{l}$ fungal ARISA PCR mastermix contained $1 \times$ PCR buffer (Qiagen Pty Ltd., Melbourne, Australia); $1.5 \mathrm{mM} \mathrm{MgCl}_{2}$ (Qiagen); $1 \times \mathrm{Q}$ reagent (Qiagen); $500 \mu \mathrm{M}$ concentration of each deoxynucleoside triphosphate (dNTP) (Qiagen); $10 \mathrm{ng}$ of extracted DNA; $500 \mathrm{nM}$ of fungal primers ITS $1 \mathrm{~F}$ (5'-CTT GGT CAT TTA GAG GAA GTA-3') and ITS 4 (5' ${ }^{\prime}$-TCC TCC GCT TAT TGA TAT GC-3') (Bioline Global Pty Ltd., NSW, Australia), the latter labeled with a phosphoramidite dye, 6FAM (Sigma Aldrich Pty Ltd., Sydney, Australia); and $3.75 \mathrm{U}$ of GoTaq polymerase (Qiagen). Reaction mixtures were held at $96^{\circ} \mathrm{C}$ for $3 \mathrm{~min}$, followed by 36 cycles of amplification at $96^{\circ} \mathrm{C}$ for $30 \mathrm{~s}, 55^{\circ} \mathrm{C}$ for $75 \mathrm{~s}$, and $72^{\circ} \mathrm{C}$ for $90 \mathrm{~s}$ and a final extension of $72^{\circ} \mathrm{C}$ for 6 min using a CFX Connect Real-Time PCR Detection System (Bio-Rad, Hercules, USA).

Bacterial community analysis by ARISA targeted the intergenic spacer region of the $16 \mathrm{~S}$ - 23S rRNA genes using the universal primer 16S - 1392f ( $5^{\prime}$ - GSA CAC ACC GCC CGT - 3'), labeled with a phosphoramidite dye, 6FAM, and bacterial primer $23 \mathrm{~S}$ - 125r (5' - GGG TTB CCC CAT TCR G - 3') (Fuhrman et al., 2008). The bacterial ARISA PCR mixture contained the same ingredients and concentrations as applied in the fungal PCR mastermix (described above), with the exception of the primers used. Reaction mixtures were held at $94^{\circ} \mathrm{C}$ for $3 \mathrm{~min}$, followed by 33 cycles of amplification at $94^{\circ} \mathrm{C}$ for $1 \mathrm{~min}, 52^{\circ} \mathrm{C}$ for $1 \mathrm{~min}$, and $72^{\circ} \mathrm{C}$ for $90 \mathrm{~s}$ and a final extension of $72^{\circ} \mathrm{C}$ for $6 \mathrm{~min}$ using a CFX Connect Real-Time PCR Detection System (Bio-Rad, Hercules, USA). PCR products were examined by gel electrophoresis on a $1.5 \%$ agarose gel matrix and imaged by fluorescence under UV light. Bacterial and fungal community analyses by ARISA were conducted by Australian Genome Research Facility as per Wood et al. (2016a,b). This involved the separation of amplicons, described as operation taxonomic units (OTUs), by capillary electrophoresis.

\section{Statistical Analysis of Automated Ribosomal Intergenic Spacer Analysis Data}

OTU fragment sizes were limited to a range of $140-1,000 \mathrm{bp}$ for both fungi and bacteria to ensure only the intergenic spacer region was represented in the data (Fisher and Triplett, 1999).
Singletons and low abundance amplicons $(<1 \%$ relative abundance) were disregarded (Fisher and Triplett, 1999). Data were normalized in the statistical software $\mathrm{R}$ version 3.3.2 (The R Foundation for Statistical Computing, Boston, USA), with bin sizes of 3 and 4 selected for bacteria and fungi, respectively (Ramette, 2009; Butterly et al., 2016). The following analyses were conducted in Primer-E v6 (Quest Research Ltd., Auckland, New Zealand), with treatments considered as fixed factors and microbial responses analyzed for each soil separately (Chow et al., 2013; Wood et al., 2016a,b): (1) Bray-Curtis similarity for microbial communities; (2) SIMPER analysis to identify the contribution of individual Operational Taxonomic Units (OTUs) to (dis)similarity between replicates or different treatments; (3) DIVERSE to determine Shannon diversity index $\left(H^{\prime}\right)$ for sample data; (4) permutational multivariate analysis of variance (PERMANOVA) to determine treatment effect (melatonin, stressors: cadmium and salt) on microbial assemblages for each soil at various concentrations (high, low, and zero). Monte Carlo statistical analysis was conducted to determine if individual treatment combinations had statistically significant effects on community compositions (Van Wijngaarden et al., 1995). Shannon's diversity index $\left(H^{\prime}\right)$ was calculated from binned data to determine differences in biodiversity (relative abundance and evenness) of taxa present within each soil for fungal and bacterial communities upon treatment with melatonin (averaged for four replicates) (Ondreičková et al., 2016). Subsequently, Shannon index values were analyzed by non-parametric Wilcoxon test to determine significant $(p<0.05)$ differences upon melatonin treatments under high or low concentration for the stressors (cadmium or Salt). Non-multidimensional scaling (nMDS) and principal coordinates analyses (PCoA) plots were generated using ggplot and phyloseq packages in the statistical software R v 3.5.2 (The R Foundation for Statistical Computing, Boston, USA) for visual representation of community (dis)similarities between samples.

\section{Microbial Biomass Response to Melatonin and Stressors}

Bacterial and fungal biomasses were measured by quantitative PCR (qPCR) on DNA of the $16 \mathrm{~s}$ rRNA and ITS region, respectively. Bacterial communities were assessed using primer pairs $1114 \mathrm{f}$ (5'-CGG CAA CGA GCG CAA CCC-3') -1275r (5'-CCA TTG 
TAG CAC GTG TGT AGC C-3'), and fungal communities were assessed using ITS1F (5' $5^{\prime}$ TCC GTA GGT GAA CCT GCG G-3') -5.8Sr (5'-CGC TGC GTT CTT CAT CG-3') primer (Wood et al., 2016a,b). Each treatment consisted of four biological replicates each quantified in technical triplicate using a CFX Connect RealTime PCR Detection System (Bio-Rad, Hercules, USA). A $20 \mu \mathrm{l}$ reaction mixture for bacterial samples was composed of $2 \mu \mathrm{l}$ extracted DNA $(0.25 \mathrm{ng} / \mu \mathrm{l})$ and $18 \mu \mathrm{l}$ mastermix according to the following recipe: $3.3 \mu$ l Universal SYBR ${ }^{\circledR}$ Green Super Mix; $0.27 \mu \mathrm{l}$ of each $10 \mu \mathrm{M}$ forward and reverse primer (135 $\mathrm{pM}$ final concentration of each primer in reaction mixture); $14.16 \mu \mathrm{l}$ DNA-free water. Bacterial qPCR reaction mixtures were held at $94^{\circ} \mathrm{C}$ for $3 \mathrm{~min}$, followed by 40 cycles of amplification at $94^{\circ} \mathrm{C}$ for $10 \mathrm{~s}, 61.5^{\circ} \mathrm{C}$ for $30 \mathrm{~s}$. Fungal samples were prepared to a $10 \mu \mathrm{l}$ reaction mixture composed of $2 \mu \mathrm{l}$ extracted DNA $(0.25 \mathrm{ng} / \mu \mathrm{l})$ and $8 \mu \mathrm{l}$ mastermix composed of $4.5 \mu \mathrm{l}$ Universal SYBR $^{\circledR}$ Green Super Mix; $0.5 \mu$ of each $10 \mu \mathrm{M}$ forward and reverse primer (500 $\mathrm{pM}$ final concentration of each primer in reaction mixture); $2.5 \mu$ l DNA-free water. Fungal qPCR conditions were $95^{\circ} \mathrm{C}$ for $5 \mathrm{~min}$, followed by 40 cycles of amplification at $95^{\circ} \mathrm{C}$ for $30 \mathrm{~s}, 53^{\circ} \mathrm{C}$ for $30 \mathrm{~s}$, and $72^{\circ} \mathrm{C}$ for $30 \mathrm{~s}$. A melting curve was measured from $65^{\circ} \mathrm{C}$ up to $95^{\circ} \mathrm{C}$ following $\mathrm{qPCR}$ reactions by increasing in $0.5^{\circ} \mathrm{C}$ increments every $30 \mathrm{~s}$. Purified amplicons from pure isolates of E. coli and Penicillium sp. cultures were used to generate standard curves (10-fold series dilutions) for bacterial and fungal samples, respectively.

\section{RESULTS}

\section{Agricultural Soils Have Diverse Microbiomes and Physiochemical Properties}

Three agricultural soils differing in land use practices, physiochemical characteristics, and microbial content were used to assess the modulatory effect of melatonin on soil community. Soils C and W were collected from sites within close geographical proximity $(<10 \mathrm{~km})$ to each other and showed the most similarity in physiochemical parameters of the three soils (Table 1). Electrical conductance substantially increased in response to both salt treatments (Table 2). The ARISA community profiles representing bacterial and fungal communities in the three dry untreated soils showed significant $(p<0.05)$ differences to each other (Figure 1). We detected a mean of 29.71, 30.00, and 36.00 bacterial OTUs, and 16.56, 16.38, and 14.75 fungal OTUs, for untreated soils $\mathrm{P}, \mathrm{C}$, and $\mathrm{W}$, respectively.

\section{Cadmium and Salt Alter Microbial Community Structures}

Stressors significantly $(p<0.05)$ impacted microbial $\beta$ diversity (Table 3). Bacterial community structures of soils $\mathrm{C}$ and $\mathrm{W}$ were substantially impacted $(p<0.01)$ by treatments with high and low concentrations of cadmium and salt (Supplementary Table S1A). Similarly, bacterial community structures in soil $\mathrm{P}$ were responsive to salt at high and low concentrations, but community structures in this soil did not show a significant response to cadmium. Fungal communities in all soils were impacted by high concentrations of cadmium and salt. In contrast, low concentrations of salt impacted fungal community structures in soil $\mathrm{C}$ and $\mathrm{W}$ (not $\mathrm{P}$ ), whereas only fungal communities in soil $\mathrm{P}$ were altered by low cadmium treatment (Supplementary Table S1B).

\section{Melatonin Affects Soil Microbial Diversity and Abundance Across all Three Soils \\ Soil Microbial Community Responses to Melatonin Under Abiotic Stress Conditions}

The addition of melatonin to all three soil types had considerable effects (increases and decreases) on the bacterial $\alpha$ diversity $(p<0.05)$ but did not significantly affect the fungal $\alpha$ diversity (Supplementary Data S1, Supplementary Table S2). Individual bacterial and fungal OTUs that responded strongly to melatonin showed relative abundances increased by up to 7.09 and $11.53 \%$ and reduced by 16.92 and $10.23 \%$, respectively (Supplementary Tables S3, S4). Analysis of the soils OTUs compositions ( $\beta$ diversity) by Permutational Multivariate Analysis of Variance (PERMANOVA) indicated that bacterial and fungal community was clearly altered by melatonin and stressors application (Table 3, Supplementary Tables S1, S5, S6). The responses of microbial communities in all soils to melatonin under abiotic stress conditions were visualized by non-metric multidimensional scaling (nMDS) ordination (Figures 2A, 3A, Supplementary Figures S1, S2). Under abiotic stress conditions, bacterial communities responding significantly $(p<0.05)$ to melatonin showed a decreased Shannon diversity index (OTU abundance and evenness), whereas fungal communities increased under the same conditions (Supplementary Data S2, Supplementary Figures S3, S4). Overall melatonin had very little effect on bacterial $16 \mathrm{~S}$ or fungal $18 \mathrm{~S}$ rDNA copy numbers, with only one soil bacterial community (Soil W) impacted $(p<0.05)$ by exogenous melatonin only, while fungal communities were unaffected by melatonin-only treatments (Supplementary Data S3, Supplementary Figures S5, S6). Some differences between treatments were recorded, however no consistent pattern of microbial biomass shift was observed under stress conditions +/- melatonin (Supplementary Data S3).

\section{Effect of Melatonin on Bacterial and Fungal Communities}

Melatonin had different impacts on bacterial versus fungal composition of soils. High melatonin concentration had a large effect (PERMANOVA: $p<0.01$ ) on bacterial community structures in all three soils, whereas low melatonin concentration impacted only bacterial communities within soil $\mathrm{C}$ and $\mathrm{W}$ (Supplementary Table S5A). Fungi responded less to melatonin compared to bacteria within the same samples. Melatonin had no effect on fungal community structures in soil C (Supplementary Table S5B), while only high melatonin concentration treatment at sampling timepoint $\mathrm{T} 1$ impacted fungal community structures in soil $\mathrm{P}$ (Table 3 ). However, melatonin at high and low concentration induced shifts in fungal community structures within soil W. 

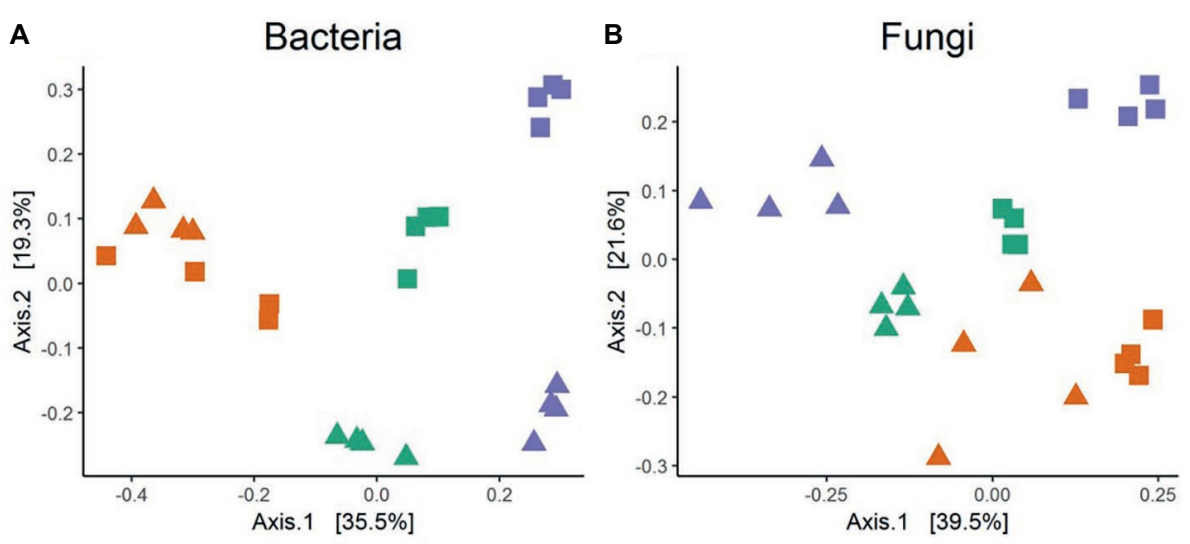

\section{$\Delta$ TO匹T1 $\bullet$ Soil C $\bullet$ Soil P $\bullet$ Soil W}

FIGURE 1 | Principal coordinates analysis (PCOA) ordination plots (Bray-Curtis distance matrix) of ARISA profiles showing the separation within (A) bacterial and (B) fungal communities for the three dry, untreated soils ( $P, C, W ; n=4)$. Bacterial communities from the same soil differed (ANOSIM: $R=0.865-1 ; p=0.029$ ) between sampling timepoints T0 and T1 within soils $\mathrm{C}$ and $\mathrm{W}$, whereas bacterial communities in soil A were not significantly different between timepoints T0 and T1 (ANOSIM: $R=0.594 ; p=0.057$ ). All untreated soil communities from different soils were dissimilar $(p<0.05)$ to each other. Fungal communities from the same soil differed (ANOSIM: $R=0.458-1 ; p=0.029$ ) between TO and T1 for all three soils.

TABLE 3 | Bacterial (1) and fungal (2) community responses to treatments ( $\beta$ diversity) with melatonin, stressors and melatonin-stressor combinations based on PERMANOVA analyses of ARISA data (Bray-Curtis dissimilarity distances).

\begin{tabular}{|c|c|c|c|c|c|c|c|}
\hline & & \multicolumn{2}{|c|}{ MT } & \multicolumn{2}{|c|}{ Stressor } & \multicolumn{2}{|c|}{ MT $\times$ Stressor } \\
\hline & & Pseudo-F & $p$ & Pseudo-F & $p$ & Pseudo-F & $p$ \\
\hline \multicolumn{8}{|c|}{ 1. Bacterial community response } \\
\hline \multirow[t]{2}{*}{ Soil P } & $\mathrm{Cd}(\mathrm{TO})$ & 1.429 & 0.1412 & 1.516 & 0.1121 & 1.975 & $0.0195^{\star}$ \\
\hline & Salt (T1) & 2.418 & $0.0006^{\star \star \star}$ & 3.072 & $0.0002^{* * *}$ & 1.425 & $0.046^{*}$ \\
\hline \multirow[t]{2}{*}{ Soil C } & $\mathrm{Cd}(\mathrm{TO})$ & 2.151 & $0.0213^{\star *}$ & 9.151 & $0.0001^{\star \star *}$ & 0.941 & 0.546 \\
\hline & Salt (T1) & 3.166 & $0.0029^{\star *}$ & 19.587 & $0.0001^{* * *}$ & 8.721 & $0.0001^{* * *}$ \\
\hline \multirow[t]{2}{*}{ Soil W } & $\mathrm{Cd}(\mathrm{TO})$ & 10.668 & $0.0001^{\star \star \star}$ & 8.795 & $0.0001^{* \star *}$ & 2.277 & $0.0001^{\star * *}$ \\
\hline & Salt (T1) & 7.839 & $0.0001^{\star \star \star}$ & 10.595 & $0.0001^{* * *}$ & 10.232 & $0.0001^{\star * *}$ \\
\hline \multicolumn{8}{|c|}{ 2. Fungal community response } \\
\hline \multirow[t]{2}{*}{ Soil P } & $\mathrm{Cd}(\mathrm{TO})$ & 1.1462 & 0.2957 & 2.8194 & $0.0008^{* * *}$ & 1.123 & 0.2854 \\
\hline & Salt (T1) & 1.4014 & 0.0811 & 1.8788 & $0.0054^{\star *}$ & 1.414 & $0.0284^{*}$ \\
\hline \multirow[t]{2}{*}{ Soil C } & $\mathrm{Cd}(\mathrm{TO})$ & 1.0284 & 0.4271 & 2.1996 & $0.0071^{\star *}$ & 1.2995 & 0.1264 \\
\hline & Salt (T1) & 1.1854 & 0.2517 & 4.2529 & $0.0001^{* \star *}$ & 1.553 & $0.0167^{*}$ \\
\hline \multirow[t]{2}{*}{ Soil W } & $\mathrm{Cd}(\mathrm{TO})$ & 4.7926 & $0.0001^{\star \star \star}$ & 1.8998 & $0.035^{\star}$ & 0.7398 & 0.8123 \\
\hline & Salt (T1) & 2.1305 & $0.0062^{\star \star}$ & 6.0265 & $0.0001^{* \star *}$ & 1.8435 & $0.0033^{\star \star}$ \\
\hline
\end{tabular}

MT, melatonin; Stressors: cadmium (Cd), Salt. Sampling timepoints: TO, T1. All treatments and controls were composed of a standardized amount of dilute ethanol. $n=4$ replicates per treatment. Significance of PERMANOVA (highlighted in bold): ${ }^{*} 0.01<p \leq 0.05 ;{ }^{* *} 0.001<p \leq 0.01 ;{ }^{* * *} \leq \leq 0.001$.

\section{Microbial Community Responses to Melatonin Under Stress Condition}

In comparison to stressor-only treatments, consistent responses to melatonin were observed in bacterial communities compared to fungal communities, especially at high melatonin concentration (Table 4, Supplementary Data S4, Supplementary Table S6). Bacterial responses to high melatonin concentration were significant (in comparison with stressor only treated communities) under high cadmium or salt conditions in soils $\mathrm{P}$ and $\mathrm{W}$, but not in soil C (Table 4). Under low stressor conditions, bacterial communities in soil $\mathrm{C}$ and soil $\mathrm{W}$ were altered $(p<0.05)$ by high melatonin treatment. In contrast, bacterial communities responded to the availability of low melatonin under high stress conditions only in soil $\mathrm{W}$ only (both stressors) and under low stressor (salt only) in soils C and W. Fungal communities were far less responsive to melatonin treatments under abiotic stress conditions. In comparison with stressor only treatments, melatonin only caused a shift in fungal communities at high melatonin treatments in soil $\mathrm{W}$ under high cadmium stress and to low melatonin under low salt stress in soil C (Table 4).

\section{Microbial Responses Within Soil W Communities}

Only soil W under salt stress showed significant $(p<0.01)$ responses to treatments of melatonin, stressor, and melatonin $\times$ stressor for both fungal and bacterial communities as described 


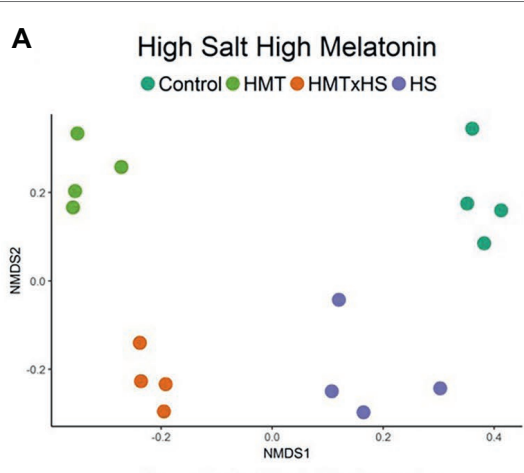

Low Salt High Melatonin

- Control $\bullet$ HMT • HMTXLS $\bullet L S$

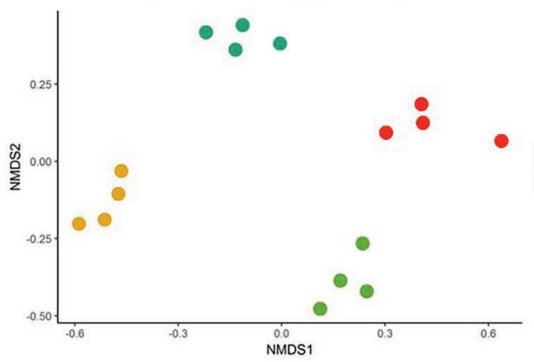

High Salt Low Melatonin

- Control $\bullet$ HS $\bullet$ LMT $\bullet$ LMTXHS

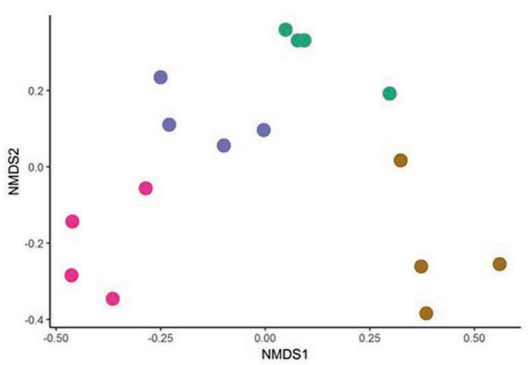

Low Salt Low Melatonin

- Control $\bullet$ LMT $\bullet$ LMTXLS•LS

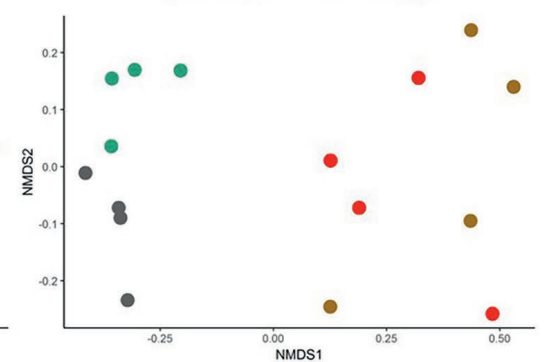

B
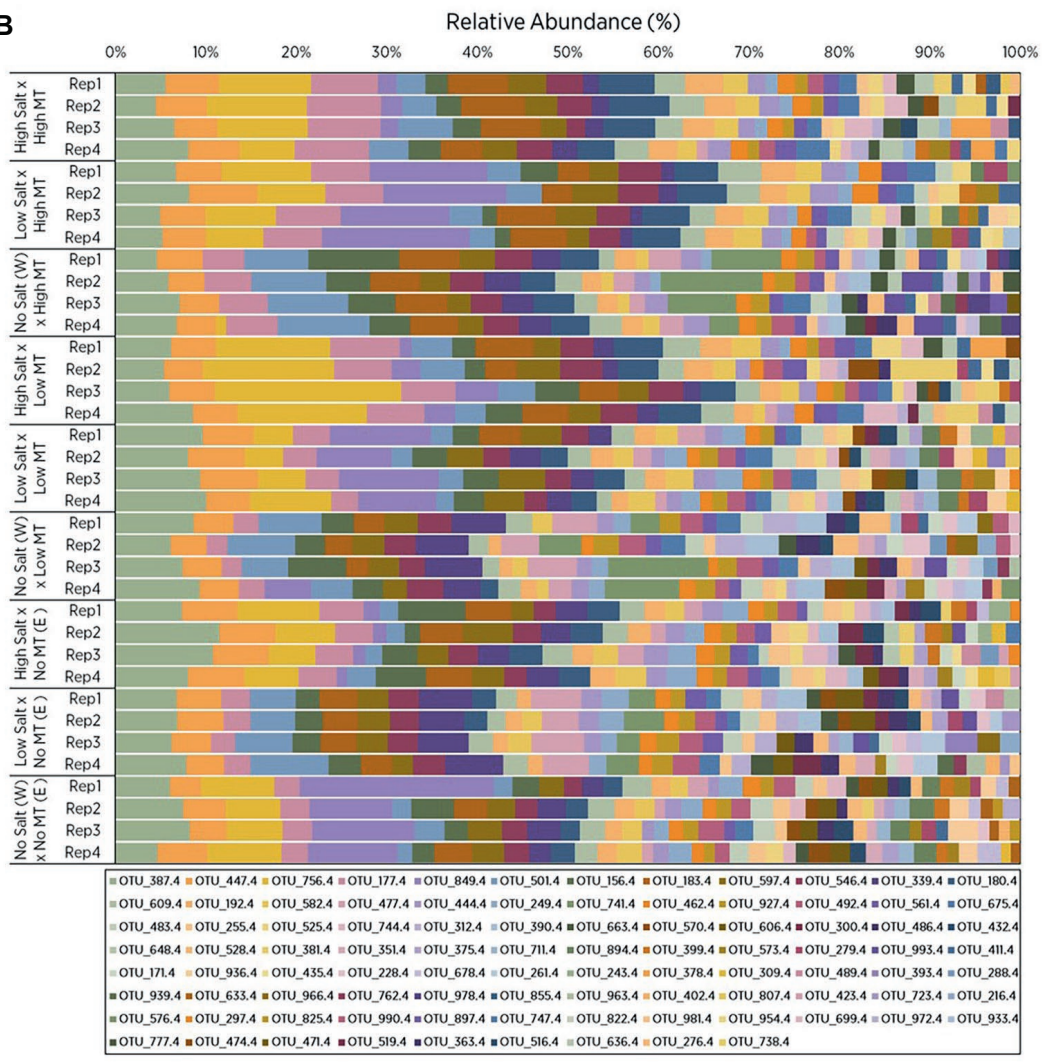

FIGURE 2 | Comparison of (A) non-metric multidimensional scaling (nMDS) ordination and (B) OTU relative abundances displaying Bray-Curtis similarities for bacterial samples within soil W for various treatments of melatonin and salt based upon community compositions determined by ARISA fingerprinting analysis. Legends in (B) represent different individual OTUs as determined by specified nucleotide lengths. The relative proximity of replicates reflects high community similarity within the same treatments for bacterial communities. Water (W) replaced salt treatment and dilute ethanol (E) replaced melatonin treatments in respective control samples. All treatments and controls were composed of a standardized amount of dilute ethanol. HMT, high melatonin; LMT, low melatonin; HS, high salt; $\mathrm{LS}$, low salt; HMT $\times$ HS, high melatonin with high salt; HMT $\times$ LS, high melatonin with low salt; LMT $\times H S$, low melatonin with high salt; LMT $\times$ LS, low melatonin with low salt. 


\section{A

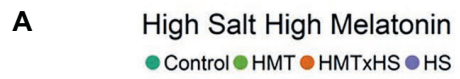

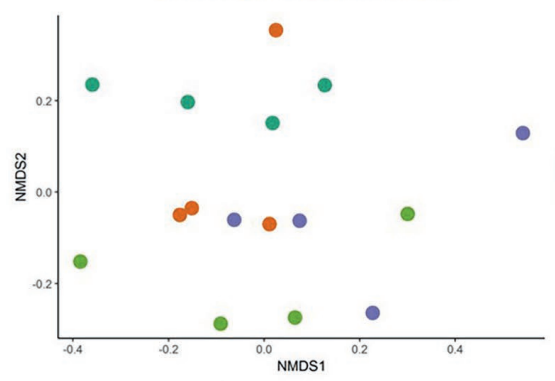

Low Salt High Melatonin

- Control • HMT • HMTXLS —LS
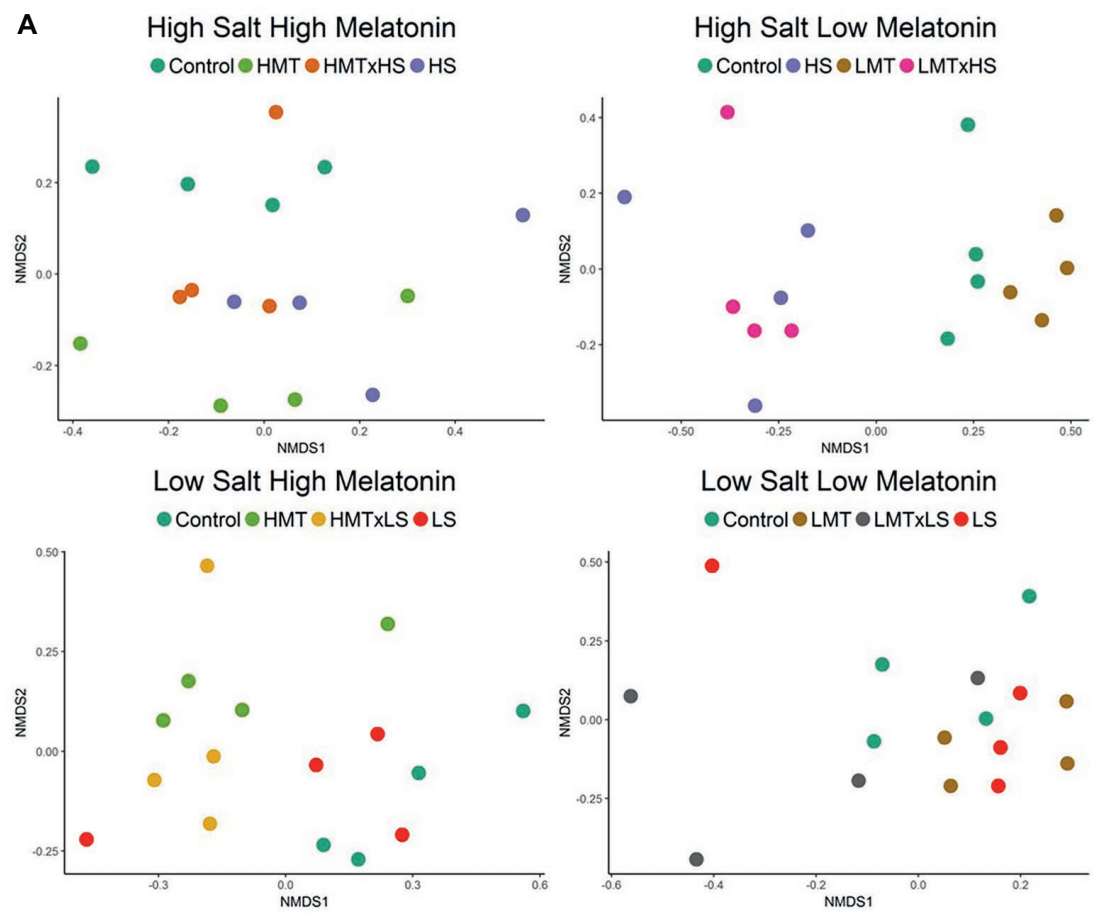

B

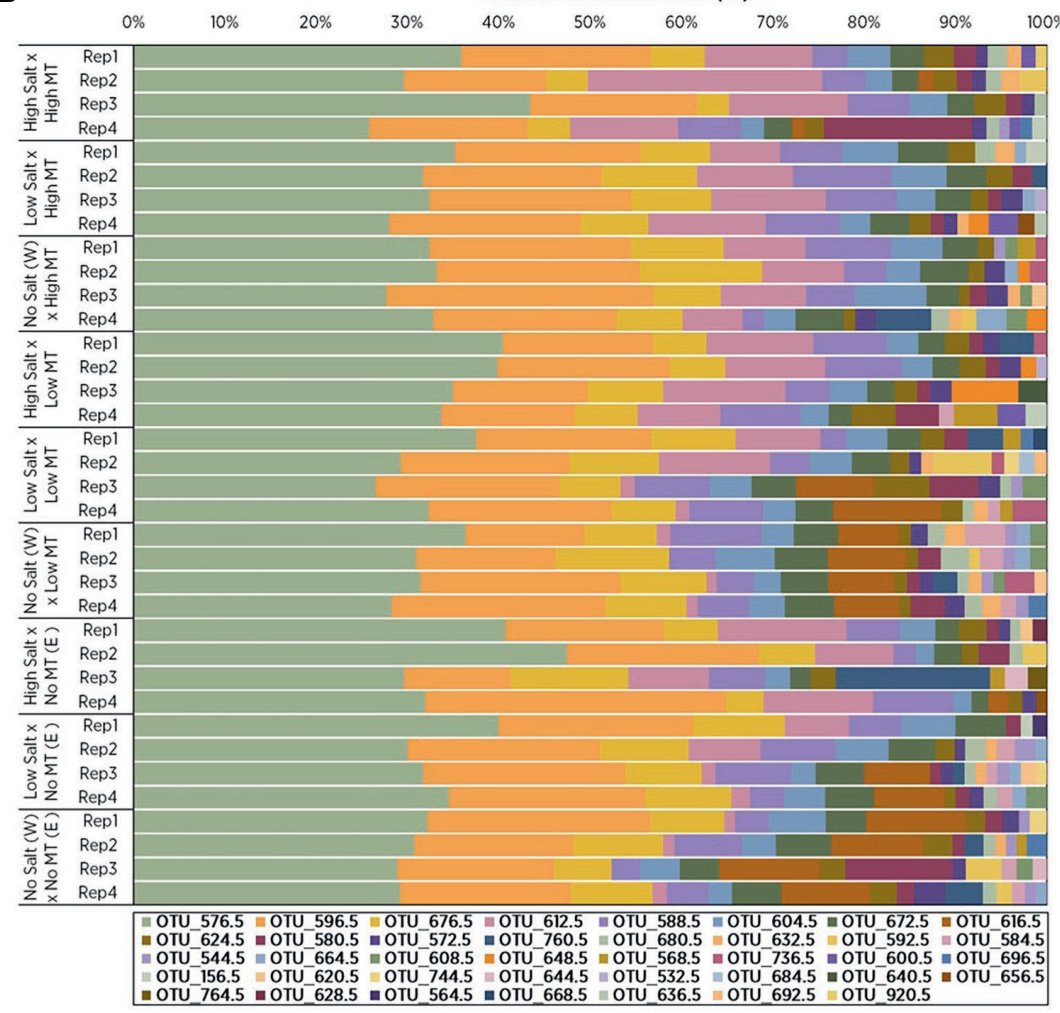

FIGURE 3 | Comparison of (A) non-metric multidimensional scaling (nMDS) ordination and (B) OTU relative abundances displaying Bray-Curtis similarities for fungal samples within soil W for various treatments of melatonin and salt based upon community compositions determined by ARISA fingerprinting analysis. Legends in (B) represent different individual OTUs as determined by specified nucleotide lengths. The relative proximity of replicates reflects high community similarity within the same treatments for fungal communities. Water (W) replaced salt treatment and dilute ethanol (E) replaced melatonin treatments in respective control samples. All treatments and controls were composed of a standardized amount of dilute ethanol. HMT, high melatonin; LMT, low melatonin; HS, high salt; LS, low salt; HMT $\times$ HS, high melatonin with high salt; HMT $\times$ LS, high melatonin with low salt; LMT $\times$ HS, low melatonin with high salt; LMT $\times$ LS, low melatonin with low salt. 
by PERMANOVA (Table 3, Supplementary Tables S1, S5, S6). These communities were subsequently assessed in greater detail.

\section{Bacterial Communities Show Distinct Responses to Melatonin Under Salt Stress (Soil W)}

The nMDS plot for bacterial assemblages showed clear separation of samples according to treatments, with both melatonin and salt treatments resulting in shifts in community structures compared to the control (Figure 2A). Various individual OTUs shifted in response to the different treatments (Figure 2B, Supplementary Figure S7A). Bacterial communities treated with melatonin were substantially different [PERMANOVA $F_{(2,}$ 27) $=7.839, p<0.001]$ to control communities, with high melatonin concentration being $50.46 \%$ dissimilar to the control treatments whereas low melatonin concentration samples showed 48.05\% dissimilarity (Supplementary Table S7A). Similarity percentage analysis (SIMPER) showed the OTUs contributing most to assemblage differences upon high melatonin treatment in comparison to control samples. This analysis found that the top three OTUs accounted for $27 \%$ of the total dissimilarity. These were OTU: 849 bp (12.88\%), 741 bp (7.32\%), and 756 bp (6.83\%). High and low concentration melatonin samples were $36.70 \%$ dissimilar to each other with 29 OTUs accounting for $71.05 \%$ of these differences, the highest of which (OTU: $180 \mathrm{bp}$ ) represented only $5.01 \%$ of the dissimilarity (Supplementary Figure S7A). Bacterial responses to both concentrations of melatonin for soil $\mathrm{W}$ were significant under high and low salt stress in comparison to the respective salt only treatments (Table 4). Under all the above comparisons, a single OTU (756 bp) consistently increased (up to $7.67 \%$ ) when melatonin was present, independent of melatonin and salt concentrations. Interestingly, some OTUs most responsive to melatonin under high salt conditions in soil W (e.g., OTU 387 bp) were far less responsive to melatonin under low salt conditions and vice versa (e.g., OTU 849 bp).

\section{Fungal Community Responses to Treatments (Melatonin and/or Salt) in Soil W}

NMDS ordination for fungal communities within soil W indicated distinct separation of samples treated with melatoninonly [PERMANOVA: $F_{(2,27)}=2.131, p<0.001$ ] and salt-only [PERMANOVA: $\left.F_{(2,27)}=6.027, p<0.001\right]$ when compared with respective control samples (Figures 3A,B). Relative abundances of individual fungal OTUs varied across all treatments in soil W under salt stress (Supplementary Figure S7B). Fungal communities in soil $\mathrm{W}$ treated with high melatonin concentration showed greater dissimilarity (33.72\%) than low melatonin-treated samples $(28.54 \%)$ when both were compared with control samples (Supplementary Table S7B), with high melatonin treatment noticeably different $(p<0.05)$ to control samples (Table 4). In soil $\mathrm{W}$ communities treated with high melatonin concentration, three taxa accounted for almost half of the total dissimilarity: OTUs 617 bp (20.05\%), 613 bp (14.05\%), and 597 bp (9.37\%). Correspondingly, OTUs 597 bp (13.63\%) and $581 \mathrm{bp}(9.23 \%)$ also accounted strongly for the community dissimilarity between control and low melatonin-treated samples

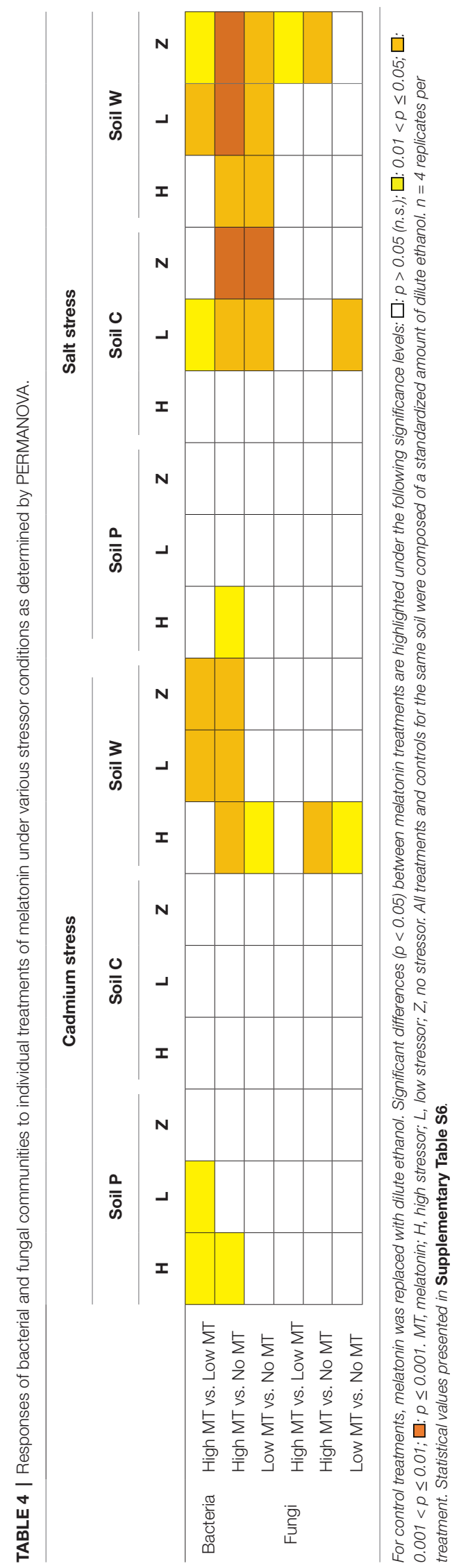


(Supplementary Figure S7B). The separation between samples treated with low melatonin concentration only compared with samples treated with both salt and low melatonin concentration was observed; however, fungal community differences were not determined as significant in response to melatonin under salt stress (Figure 3A, Table 4).

\section{DISCUSSION}

Soil microbial communities are a key component of a healthy ecosystem, providing a number of ecosystem services including direct and indirect nourishments of plant root systems (Wall and Virginia, 1999; Yao et al., 2000; Kirk et al., 2004; Wahid et al., 2016). We detected significant responses of microbes at a community level to melatonin treatment under normal or abiotic stress conditions in agricultural top-soils $(10 \mathrm{~cm}$ depth). These responses varied slightly according to the melatonin dose and differed considerably between bacteria and fungi. As shifts in soil microbial communities may result in changes to various ecosystem services provided by soil microbes (Mau et al., 2019; Zhang et al., 2019), understanding how soil microbes respond to melatonin may be an important aspect in determining the viability of potential future agricultural applications of melatonin.

The doses of melatonin chosen in the current study (4 and $0.2 \mathrm{mg} \mathrm{kg}^{-1}$ soil) correspond to equivalent concentrations of approximately 100 and $5 \mu \mathrm{M}$, respectively. Enhanced abiotic stress tolerance as well as bio-stimulation have been reported in plants treated with exogenous melatonin within relative close proximity to either of these concentrations (Zhang et al., 2015; Nawaz et al., 2016; Sharif et al., 2018; Wang et al., 2018; Debnath et al., 2019). Therefore, these doses have biological relevance related to future melatonin applications in agriculture. Foliar spray of $100 \mu \mathrm{M}$ melatonin on wheat (Triticum aestivum L. cv. Pandas) resulted in enhanced plant growth and reduced oxidative damage caused by exposure to cadmium (Kaya et al., 2019). Similarly, tolerance to salinity stress was increased in Malus huphensis upon pre-treatment with $100 \mu \mathrm{M}$ melatonin (Li et al., 2012). Various studies also present the beneficial effect of low melatonin treatments $(\leq 10 \mu \mathrm{M})$ for plants. For example, pre-treatment of oxidatively stressed Arabidopsis with $5 \mu \mathrm{M}$ melatonin resulted in strong upregulation of genes involved in autophagy (Wang et al., 2015). Seed germination and seed imbibition were improved by $1 \mu \mathrm{M}$ melatonin under salt stress conditions (Zhang et al., 2017a,b).

We hypothesized that melatonin would alter soil microbial community structures, as previous reports suggest that melatonin may act with antimicrobial properties. For example, melatonin was shown to inhibit the in vitro growth of the human bacterial pathogens, Staphylococcus aureus, Pseudomonas aeruginosa, and Acinetobacter baumannii at concentrations between 130 and $530 \mu \mathrm{M}$ (Tekbas et al., 2008). Melatonin has also been reported to inhibit the in vitro growth of the human pathogenic yeast, Candida albicans, albeit at a much higher concentration $(1,300 \mu \mathrm{M})$ (Öztürk et al., 2000). Our community study complements these findings, as bacteria associated with the three different agricultural soils were affected by melatonin alone. We also hypothesized that fungal communities would be less responsive to melatonin compared with bacteria, as previous in vitro studies have indicated limited responses to melatonin by fungi (Table 2, Supplementary Table S6). For example, in vitro studies investigating responses of filamentous fungi to melatonin found that at very high concentration $(100 \mathrm{mM})$, melatonin showed no impact on the in vitro growth of Physalospora piricola, Botrytis cinerea or Mycosphaerella arachidicola (Wang et al., 2001). Growth of Alternaria spp. has been reported to be inhibited at a relatively high melatonin concentration (4 mM) (Arnao and Hernández-Ruiz, 2015).

Fungal communities responded far less to exogenous melatonin compared to bacteria in our studies (Table 3). One important factor influencing the limited responses of fungal communities to melatonin may have been the duration of incubation. In our current study, the 10-day incubation period was selected to accommodate both bacterial and fungal responses to treatments. Microbial activity is generally considered to be stabilized 7-10 days post-treatment exposure (Chowdhury et al., 2011). However, a longer incubation duration may have allowed a greater fungal community response as slower growing fungi would have had more time to sufficiently respond to melatonin treatments.

Both melatonin doses resulted in distinct shifts of bacterial and fungal communities, with high melatonin treatments resulting in slightly greater shift compared to low doses (Table 4). Melatonin may be utilized more efficiently by some microbes compared to others under the various experimental conditions, thus, potentially offering a competitive advantage to select groups. Our study indicated that some microbes accounted strongly for the shifts in communities treated with melatonin across the three soils (Supplementary Tables S3, S4; Supplementary Figure S7). Some root-dwelling bacteria have been shown to secrete melatonin (Jiao et al., 2016). The plant hormone Indole3 -acteic acid (IAA) is structurally similar to melatonin (Arnao and Hernandez-Ruiz, 2014) and has been shown to act as a signaling molecule between soil bacteria, fungi, and plant roots, resulting in a complex dynamic of responses by individual microbes within the rhizosphere community (Lambrecht et al., 2000; Lee and Lee, 2010; Spaepen and Vanderleyden, 2011; Fu et al., 2015). Therefore, investigating the possibility that melatonin may also be utilized in the rhizosphere to influence microbial community dynamics is worthy of further research.

Recently, Li et al. (2018) investigated the effect of exogenous melatonin application $(200 \mu \mathrm{M}$; applied at 20-day intervals for 6 months), without abiotic stress, in two soils types associated with horticultural practices (apple orchard and vegetables) by sampling the subsoil region $(20-30 \mathrm{~cm}$ depth). Bacterial compositions of melatonin-treated soil samples were shown to be similar to controls; however, some genera, many unknown, shifted strongly in response to melatonin (Li et al., 2018). In fungal assemblages, Ascomycota, in particular, were negatively affected by melatonin, resulting in a greater establishment of Glomeromycota and Basidiomycota (Li et al., 2018). While a direct comparison between our study and this report is difficult, these results are analogous to the trends observed in our investigation and indicative of the importance of soil agricultural 
histories in microbial response to melatonin. In our study, we used topsoils, which are generally more microbially rich (compared to subsoils), as well as soils associated with agricultural practices (crop production and pasture). Further analysis by taxa identification of the soil microbial communities associated with responses to melatonin would determine those microbes associated with particular ecological niches (e.g., mycorrhizal fungi or plant growth-promoting rhizobacteria) and if they are known to be beneficial to crops. Based on our findings, we recommend that plant-based studies applying melatonin through the soil should also take into consideration the effect treatments may have on soil microbes as part of their investigations.

The responses by bacteria to melatonin under unstressed and stressed conditions were not consistent across the three soils (Table 4), indicating that numerous factors may determine the interactions of soil bacteria with melatonin. These different responses may have been in part due to differing soil physiochemical characteristics between the soils, as well as differing interactive effects of treatments with various soil characteristics (Zhong and Cai, 2007; Ahn et al., 2012; Zhao et al., 2014; Geisseler et al., 2017). In the current study, some communities were less impacted by abiotic stress upon the availability of exogenous melatonin. However, as this trend was not observed under cadmium stress, it may be possible that melatonin was utilized by soil bacteria to sustain natural microbial activity by coping with impacts specific to salt stress, such as enhanced osmotic pressure and ion toxicity (Morrissey et al., 2014; Yan et al., 2015).

Melatonin has been consistently shown to reduce cellular levels of ROS in plants exposed to abiotic stress (Tan et al., 2012), by either acting as a highly efficient antioxidant (Reiter et al., 2015, 2016), or as a signaling molecule, resulting in the upregulation of gene expression, or increased enzyme activities of ROS-scavenging enzymes (Rodriguez et al., 2004; Lee et al., 2014; Manchester et al., 2015; Zhang et al., 2015; Nawaz et al., 2018). Under abiotic stresses, such as cadmium and salt, plants can cope better by adjusting physiological and enzymatic processes when melatonin is applied (Li et al., 2012, 2016; Byeon et al., 2015; Liang et al., 2015; Jiang et al., 2016; $\mathrm{Gu}$ et al., 2017). Some reports also suggested that melatonin may enhance abiotic stress tolerance in microbes as endogenous levels of melatonin increased in Trichoderma spp. (Liu et al., 2016) and Saccharomyces cerevisiae (Rodriguez-Naranjo et al., 2012) under abiotic stresses (cadmium and ethanol respectively).

Plant growth and development are greatly impacted on soils contaminated with cadmium or salt, resulting in reduced crop yield and food quality (Qadir et al., 2014; Shao et al., 2019; Wang et al., 2019). Cadmium chloride hemipentahydrate $\left(\mathrm{CdCl}_{2} \cdot 2 \frac{1}{2} \mathrm{H}_{2} \mathrm{O} ; 280\right.$ or $100 \mathrm{mg} \mathrm{kg}^{-1}$ soil) and salt $(\mathrm{NaCl} ; 7$ or $4 \mathrm{~g} \mathrm{~kg}^{-1}$ soil) were separately applied as abiotic stressors in the current study. These stressor concentrations were selected to be within the range of those reported to induce effects on soil microbial activities in previous studies for cadmium (Cáliz et al., 2013; Wood et al., 2016a,b) and salt (Rath et al., 2016). For example, Wood et al. (2016a,b) found that soil treated with cadmium chloride $\left(\mathrm{CdCl}_{2}\right)$ at $100 \mathrm{mg} \mathrm{kg}{ }^{-1}$ soil resulted in significant shifts in bacterial community structures, whereas fungal communities were unaffected at this concentration of soil contamination. Cáliz et al. (2013) found that significant impacts to microbial communities in soils are treated with cadmium sulphate $\left(\mathrm{CdSO}_{4}\right)$ at $1,000 \mathrm{mg} \mathrm{kg}$ soil. Salinity altered the bacterial and fungal community structures of root microsymbionts associated with alder (Alnus glutinosa) (Thiem et al., 2018). Rath et al. (2016) found effects on soil bacterial and fungal growth as well as microbial respiration at 63,55 , and $79 \mathrm{mmol} \mathrm{NaCl} \mathrm{kg} \mathrm{kg}^{-1}$ soil, respectively. This corresponds to similar concentrations of $\mathrm{NaCl}$ applied in the current experiment for $4 \mathrm{~g} \mathrm{~kg}^{-1}$ (70-96 mmol $\mathrm{NaCl} \mathrm{kg} \mathrm{kg}^{-1}$ soil). Our results indicate that the stressor concentrations affected bacterial and fungal community structures in all three soils (Table 3). Previous soil studies have found soil bacterial communities to be more responsive to various stress treatments in comparison to fungal communities, with fungi showing greater tolerance to abiotic stressors (Hiroki, 1992; Müller et al., 2001; Marschner et al., 2003; Rajapaksha et al., 2004). Interestingly, we found that bacterial communities showed more distinct responses to melatonin under abiotic stress conditions compared to fungi, along with more distinct separation of communities per treatment (e.g., Soil W). This may potentially suggest that bacteria utilized melatonin better than fungi under abiotic stress conditions.

As melatonin is safe for human consumption and can be applied to plants in numerous ways such as seed coating, foliar spraying or soil treatment, it may, therefore, have a major role in future agricultural practices for crop yield protection and improvement (Janas and Posmyk, 2013; Wei et al., 2015; Cui et al., 2017; Zhang et al., 2017a,b). Higher amounts of melatonin in foods due to exogenous application on crops and vegetables have a potential beneficial effect on human health, especially if it results in a reduced dependency on pesticide practices in agriculture. However, the chemically synthetized melatonin powder used in this study ( $>98 \%$ purity) costs AU $\$ 146$ per gram (Sigma Aldrich Pty. Ltd., Australia), and at that price, it would not be cost-effective for use in agriculture, even with a highly efficient application such as seed coating for example. Although some other "melatonin powder" can be purchased online and at cheaper cost there is few to no information about their provenance and quality. Further research is required to ensure the efficacy of lower grade melatonin for agricultural use matches that of the pure powder form. A recent study reported the production of melatonin by yeast (S. cerevisiae) using a glucose-based approach (Germann et al., 2016). This potentially offers a far more sustainable and economical method of producing melatonin. Developing an affordable, large-scale method of producing melatonin is a vital logistical aspect regarding the future use of melatonin in agricultural practices.

\section{CONCLUSION}

In conclusion, this study has demonstrated that exogenous melatonin altered the structures of soil bacterial and, to a lesser extent, fungal assemblages under unstressed and abiotic stressed conditions. No previous reports have examined the effects of melatonin on agricultural soil microbial communities under 
abiotic stress. Some bacterial and fungal OTUs responded strongly (positively or negatively) to melatonin, indicating that melatonin may alter the growth of specific groups of microbes. At a community level, responses to treatments varied across the three soils, indicating that the interaction between soil microbes with melatonin is a complex process, influenced by numerous factors including physiochemical characteristics and differing community compositions across soils. Further research is required to profile the microbial taxa responsive to melatonin as well as investigate potential functional associations between melatonin with abiotic stress tolerance in microbes. The main factors (e.g., soil chemistry) causing the differences in natural microbial communities between the different soils also requires further analysis. Additional research is also required to determine if specific soil characteristics influence the responses of microbial communities to melatonin. Moreover, studies may explore potential plant-microbe interactions in soil upon the bioavailability of exogenous melatonin. Future studies involving ameliorating plant stress using melatonin should take into account the potential impact of soil microbiota and the subsequent impact on plant-microbe interactions (beneficial as well as pathogenic). Understanding the role of melatonin in soil microbial community dynamics may provide vital information regarding the viability of melatonin application relating to future agricultural practices.

\section{DATA AVAILABILITY STATEMENT}

All datasets generated for this study are included in the article/Supplementary Material.

\section{REFERENCES}

Achard-Joris, M., Moreau, J. L., Lucas, M., Baudrimont, M., Mesmer-Dudons, N., Gonzalez, P., et al. (2007). Role of metallothioneins in superoxide radical generation during copper redox cycling: defining the fundamental function of metallothioneins. Biochimie 89, 1474-1488. doi: 10.1016/j.biochi.2007.06.005

Ahn, J. H., Song, J., Kim, B. Y., Kim, M. S., Joa, J. H., and Weon, H. Y. (2012). Characterization of the bacterial and archaeal communities in rice field soils subjected to long-term fertilization practices. J. Microbiol. 50, 754-765. doi: 10.1007/s12275-012-2409-6

Arnao, M. B., and Hernandez-Ruiz, J. (2014). Melatonin: plant growth regulator and/or biostimulator during stress? Trends Plant Sci. 19, 789-797. doi: 10.1016/j.tplants.2014.07.006

Arnao, M. B., and Hernández-Ruiz, J. (2015). Functions of melatonin in plants: a review. J. Pineal Res. 59, 133-150. doi: 10.1111/jpi.12253

Aye, N. S., Sale, P. W. G., and Tang, C. (2016). The impact of long-term liming on soil organic carbon and aggregate stability in low-input acid soils. Biol. Fertil. Soils 52, 697-709. doi: 10.1007/s00374-016-1111-y

Badri, D. V., and Vivanco, J. M. (2009). Regulation and function of root exudates. Plant Cell Environ. 32, 666-681. doi: 10.1111/j.1365-3040.2009.01926.x

Bencherif, K., Boutekrabt, A., Fontaine, J., Laruelle, F., Dalpè, Y., and Anissa, L. H. S. (2015). Impact of soil salinity on arbuscular mycorrhizal fungi biodiversity and microflora biomass associated with Tamarix articulata Vahll rhizosphere in arid and semi-arid Algerian areas. Sci. Total Environ. 533, 488-494. doi: 10.1016/j.scitotenv.2015.07.007

Blaalid, R., Kumar, S., Nilsson, R. H., Abarenkov, K., Kirk, P. M., and Kauserud, H. (2013). ITS1 versus ITS2 as DNA metabarcodes for fungi. Mol. Ecol. Resour. 13, 218-224. doi: 10.1111/1755-0998.12065

Burns, J. H., Anacker, B. L., Strauss, S. Y., and Burke, D. J. (2015). Soil microbial community variation correlates most strongly with plant species identity,

\section{AUTHOR CONTRIBUTIONS}

$\mathrm{AM}, \mathrm{FB}, \mathrm{AF}$, and $\mathrm{KP}$ conceived and designed the study. AM performed the experiments and data analysis with the assistance of $\mathrm{EE}$, and $\mathrm{AM}$ interpreted the results and wrote the manuscript with suggestions from FB and KP. All authors discussed the results and commented on the manuscript. AF and KP financed the research.

\section{FUNDING}

This work was funded by an International Postgraduate Research Scholarship (IPRS) and Australian Postgraduate Award (APA) provided by La Trobe University, Australia.

\section{ACKNOWLEDGMENTS}

Soils were sampled with the permissions of Rob Binks in Yaloak estate, Bullan, VIC, and Gary Clarke in Melbourne Polytechnic Farm, Yan Yean, VIC, Australia. This manuscript has been released as a Pre-Print at bioRxiv (Madigan et al., 2019).

\section{SUPPLEMENTARY MATERIAL}

The Supplementary Material for this article can be found online at: https://www.frontiersin.org/articles/10.3389/fmicb.2019.02616/ full\#supplementary-material followed by soil chemistry, spatial location and plant genus. AoB Plants 7, pii: plv030. doi: 10.1093/aobpla/plv030

Butterly, C. R., Phillips, L. A., Wiltshire, J. L., Franks, A. E., Armstrong, R. D., Chen, D., et al. (2016). Long-term effects of elevated $\mathrm{CO}_{2}$ on carbon and nitrogen functional capacity of microbial communities in three contrasting soils. Soil Biol. Biochem. 97, 157-167. doi: 10.1016/j.soilbio.2016.03.010

Byeon, Y., Lee, H. Y., Hwang, O. J., Lee, H. J., Lee, K., and Back, K. (2015). Coordinated regulation of melatonin synthesis and degradation genes in rice leaves in response to cadmium treatment. J. Pineal Res. 58, 470-478. doi: $10.1111 /$ jpi.12232

Cáliz, J., Montserrat, G., Martí, E., Sierra, J., Chung, A. P., Morais, P. V., et al. (2013). Emerging resistant microbiota from an acidic soil exposed to toxicity of $\mathrm{Cr}, \mathrm{Cd}$ and $\mathrm{Pb}$ is mainly influenced by the bioavailability of these metals. J. Soils Sediments 13, 413-428. doi: 10.1007/s11368-012-0609-7

Castro, H. F., Classen, A. T., Austin, E. E., Norby, R. J., and Schadt, C. W. (2010). Soil microbial community responses to multiple experimental climate change drivers. Appl. Environ. Microbiol. 76, 999-1007. doi: 10.1128/AEM.02874-09

Chen, C. Q., Fichna, J., Bashashati, M., Li, Y. Y., and Storr, M. (2011). Distribution, function and physiological role of melatonin in the lower gut. World J. Gastroenterol. 17, 3888-3898. doi: 10.3748/wjg.v17.i34.3888

Cheng, K., Tian, H. Z., Zhao, D., Lu, L., Wang, Y., Chen, J., et al. (2014). Atmospheric emission inventory of cadmium from anthropogenic sources. Int. J. Environ. Sci. Technol. 11, 605-616. doi: 10.1007/s13762-013-0206-3

Chow, C. E. T., Sachdeva, R., Cram, J. A., Steele, J. A., Needham, D. M., Patel, A., et al. (2013). Temporal variability and coherence of euphotic zone bacterial communities over a decade in the Southern California bight. ISME J. 7, 2259-2273. doi: 10.1038/ismej.2013.122

Chowdhury, N., Marschner, P., and Burns, R. G. (2011). Soil microbial activity and community composition: impact of changes in matric and osmotic potential. Soil Biol. Biochem. 43, 1229-1236. doi: 10.1016/j.soilbio.2011.02.012 
Cui, G., Zhao, X., Liu, S., Sun, F., Zhang, C., and Xi, Y. (2017). Beneficial effects of melatonin in overcoming drought stress in wheat seedlings. Plant Physiol. Biochem. 118, 138-149. doi: 10.1016/j.plaphy.2017.06.014

Debnath, B., Islam, W., Li, M., Sun, Y., Lu, X., Mitra, S., et al. (2019). Melatonin mediates enhancement of stress tolerance in plants. Int. J. Mol. Sci. 20, pii: E1040. doi: 10.3390/ijms20051040

Fisher, M. M., and Triplett, E. W. (1999). Automated approach for ribosomal intergenic spacer analysis of microbial diversity and its application to freshwater bacterial communities. Appl. Environ. Microbiol. 65, 4630-4636.

Franzaring, J., Fangmeier, A., Schlosser, S., and Hahn, V. (2019). Cadmium concentrations in German soybeans are elevated in conurbations and in regions dominated by mining and the metal industry. J. Sci. Food Agric. 99, 3711-3715. doi: 10.1002/jsfa.9548

Fu, S. F., Wei, J. Y., Chen, H. W., Liu, Y. Y., Lu, H. Y., and Chou, J. Y. (2015). Indole-3-acetic acid: a widespread physiological code in interactions of fungi with other organisms. Plant Signal. Behav. 10:e1048052. doi: 10.1080/ 15592324.2015.1048052

Fuhrman, J. A., Steele, J. A., Hewson, I., Schwalbach, M. S., Brown, M. V., Green, J. L., et al. (2008). A latitudinal diversity gradient in planktonic marine bacteria. Proc. Natl. Acad. Sci. USA 105, 7774-7778. doi: 10.1073/pnas.0803070105

Geisseler, D., Linquist, B. A., and Lazicki, P. A. (2017). Effect of fertilization on soil microorganisms in paddy rice systems - a meta-analysis. Soil Biol. Biochem. 115, 452-460. doi: 10.1016/j.soilbio.2017.09.018

Germann, S. M., Baallal Jacobsen, S. A., Schneider, K., Harrison, S. J., Jensen, N. B., Chen, X., et al. (2016). Glucose-based microbial production of the hormone melatonin in yeast Saccharomyces cerevisiae. Biotechnol. J. 11, 717-724. doi: 10.1002/biot.201500143

Gu, Q., Chen, Z., Yu, X., Cui, W., Pan, J., Zhao, G., et al. (2017). Melatonin confers plant tolerance against cadmium stress via the decrease of cadmium accumulation and reestablishment of microRNA-mediated redox homeostasis. Plant Sci. 261, 28-37. doi: 10.1016/j.plantsci.2017.05.001

Hardeland, R. (2015). Melatonin in plants and other phototrophs: advances and gaps concerning the diversity of functions. J. Exp. Bot. 66, 627-646. doi: $10.1093 / \mathrm{jxb} / \mathrm{eru} 386$

Hardeland, R. (2016). Melatonin in plants - diversity of levels and multiplicity of functions. Front. Plant Sci. 7:108. doi: 10.3389/fpls.2016.00198

He, Y., DeSutter, T., Prunty, L., Hopkins, D., Jia, X., and Wysocki, D. A. (2012). Evaluation of $1: 5$ soil to water extract electrical conductivity methods. Geoderma 185-186, 12-17. doi: 10.1016/j.geoderma.2012.03.022

Heijboer, A., De Ruiter, P. C., Bodelier, P. L. E., and Kowalchuk, G. A. (2018). Modulation of litter decomposition by the soil microbial food web under influence of land use change. Front. Microbiol. 9:2860. doi: 10.3389/ fmicb. 2018.02860

Hiroki, M. (1992). Effects of heavy metal contamination on soil microbial population. Soil Sci. Plant Nutr. 38, 141-147. doi: 10.1080/00380768. 1992.10416961

Hossain, S. T., Mallick, I., and Mukherjee, S. K. (2012). Cadmium toxicity in Escherichia coli: cell morphology, Z-ring formation and intracellular oxidative balance. Ecotoxicol. Environ. Saf. 86, 54-59. doi: 10.1016/j.ecoenv.2012.09.017

Janas, K. M., and Posmyk, M. M. (2013). Melatonin, an underestimated natural substance with great potential for agricultural application. Acta Physiol. Plant. 35, 3285-3292. doi: 10.1007/s11738-013-1372-0

Jiang, C., Cui, Q., Feng, K., Xu, D., Li, C., and Zheng, Q. (2016). Melatonin improves antioxidant capacity and ion homeostasis and enhances salt tolerance in maize seedlings. Acta Physiol. Plant. 38:82. doi: 10.1007/s11738-016-2101-2

Jiao, W., Chen, W., Chang, A. C., and Page, A. L. (2012). Environmental risks of trace elements associated with long-term phosphate fertilizers applications: a review. Environ. Pollut. 168, 44-53. doi: 10.1016/j.envpol.2012.03.052

Jiao, J., Ma, Y., Chen, S., Liu, C., Song, Y., Qin, Y., et al. (2016). Melatoninproducing endophytic bacteria from grapevine roots promote the abiotic stress-induced production of endogenous melatonin in their hosts. Front. Plant Sci. 7:1387. doi: 10.3389/fpls.2016.01387

Kaya, C., Okant, M., Ugurlar, F., Alyemeni, M. N., Ashraf, M., and Ahmad, P. (2019). Melatonin-mediated nitric oxide improves tolerance to cadmium toxicity by reducing oxidative stress in wheat plants. Chemosphere 225, 627-638. doi: 10.1016/j.chemosphere.2019.03.026

Ke, Q., Kim, H. S., Wang, Z., Ji, C. Y., Jeong, J. C., Lee, H. S., et al. (2017). Down-regulation of GIGANTEA-like genes increases plant growth and salt stress tolerance in poplar. Plant Biotechnol. J. 15, 331-343. doi: 10.1111/pbi.12628
Kelly, J. J., Häggblom, M., and Tate Iii, R. L. (1999). Changes in soil microbial communities over time resulting from one time application of zinc: a laboratory microcosm study. Soil Biol. Biochem. 31, 1455-1465. doi: 10.1016/ S0038-0717(99)00059-0

Khairy, M., El-Safty, S. A., and Shenashen, M. A. (2014). Environmental remediation and monitoring of cadmium. TrAC, Trends Anal. Chem. 62, 56-68. doi: 10.1016/j.trac.2014.06.013

Kirk, J. L., Beaudette, L. A., Hart, M., Moutoglis, P., Klironomos, J. N., Lee, H., et al. (2004). Methods of studying soil microbial diversity. J. Microbiol. Methods 58, 169-188. doi: 10.1016/j.mimet.2004.04.006

Lambrecht, M., Okon, Y., Vande Broek, A., and Vanderleyden, J. (2000). Indole-3acetic acid: a reciprocal signalling molecule in bacteria-plant interactions. Trends Microbiol. 8, 298-300. doi: 10.1016/S0966-842X(00)01732-7

Lee, H. Y., Byeon, Y., and Back, K. (2014). Melatonin as a signal molecule triggering defense responses against pathogen attack in Arabidopsis and tobacco. J. Pineal Res. 57, 262-268. doi: 10.1111/jpi.12165

Lee, J. H., and Lee, J. (2010). Indole as an intercellular signal in microbial communities. FEMS Microbiol. Rev. 34, 426-444. doi: 10.1111/j.1574-6976.2009.00204.x

Li, M. Q., Hasan, M. K., Li, C. X., Ahammed, G. J., Xia, X. J., Shi, K., et al. (2016). Melatonin mediates selenium-induced tolerance to cadmium stress in tomato plants. J. Pineal Res. 61, 291-302. doi: 10.1111/jpi.12346

Li, C., Wang, P., Wei, Z., Liang, D., Liu, C., Yin, L., et al. (2012). The mitigation effects of exogenous melatonin on salinity-induced stress in Malus hupehensis. J. Pineal Res. 53, 298-306. doi: 10.1111/j.1600-079X.2012.00999.x

Li, C., Zhao, Q., Gao, T., Wang, H., Zhang, Z., Liang, B., et al. (2018). The mitigation effects of exogenous melatonin on replant disease in apple. J. Pineal Res. 65:e12523. doi: 10.1111/jpi.12523

Liang, C., Zheng, G., Li, W., Wang, Y., Hu, B., Wang, H., et al. (2015). Melatonin delays leaf senescence and enhances salt stress tolerance in rice. J. Pineal Res. 59, 91-101. doi: 10.1111/jpi.12243

Liu, T., Zhao, F., Liu, Z., Zuo, Y., Hou, J., and Wang, Y. (2016). Identification of melatonin in Trichoderma spp. and detection of melatonin content under controlled-stress growth conditions from T. asperellum. J. Basic Microbiol. 56, 838-843. doi: 10.1002/jobm.201500223

Lucchelli, A., Santagostino-Barbone, M. G., and Tonini, M. (1997). Investigation into the contractile response of melatonin in the Guinea-pig isolated proximal colon: the role of 5-HT4 and melatonin receptors. Br. J. Pharmacol. 121, 1775-1781. doi: 10.1038/sj.bjp.0701287

Madigan, A. P., Egidi, E., Bedon, F., Franks, A. E., and Plummer, K. M. (2019). Bacterial and fungal communities are differentially modified by melatonin in agricultural soils under abiotic stress. 652388. bioRxiv [Preprint]. doi: $10.1101 / 652388$

Manchester, L. C., Coto-Montes, A., Boga, J. A., Andersen, L. P. H., Zhou, Z., Galano, A., et al. (2015). Melatonin: an ancient molecule that makes oxygen metabolically tolerable. J. Pineal Res. 59, 403-419. doi: 10.1111/jpi.12267

Marschner, P., Kandeler, E., and Marschner, B. (2003). Structure and function of the soil microbial community in a long-term fertilizer experiment. Soil Biol. Biochem. 35, 453-461. doi: 10.1016/S0038-0717(02)00297-3

Mau, R. L., Dijkstra, P., Schwartz, E., Koch, B. J., and Hungate, B. A. (2019). Addressing strengths and weaknesses of a multi-ecosystem climate change experiment. Appl. Soil Ecol. 133, 191-192. doi: 10.1016/j.apsoil.2018.07.003

Morrissey, E. M., Gillespie, J. L., Morina, J. C., and Franklin, R. B. (2014). Salinity affects microbial activity and soil organic matter content in tidal wetlands. Glob. Chang. Biol. 20, 1351-1362. doi: 10.1111/gcb.12431

Müller, A. K., Westergaard, K., Christensen, S., and Sørensen, S. J. (2001). The effect of long-term mercury pollution on the soil microbial community. FEMS Microbiol. Ecol. 36, 11-19. doi: 10.1016/S0168-6496(01)00112-X

Nawaz, M. A., Huang, Y., Bie, Z., Ahmed, W., Reiter, R. J., Niu, M., et al. (2016). Melatonin: current status and future perspectives in plant science. Front. Plant Sci. 6:1230. doi: 10.3389/fpls.2015.01230

Nawaz, M. A., Jiao, Y., Chen, C., Shireen, F., Zheng, Z., Imtiaz, M., et al. (2018). Melatonin pretreatment improves vanadium stress tolerance of watermelon seedlings by reducing vanadium concentration in the leaves and regulating melatonin biosynthesis and antioxidant-related gene expression. J. Plant Physiol. 220, 115-127. doi: 10.1016/j.jplph.2017.11.003

Ondreičková, K., Žofajová, A., Piliarová, M., Gubiš, J., and Hudcovicová, M. (2016). Monitoring of rhizosphere bacterial communities in soil with sewage sludge addition using two molecular fingerprinting methods: do these methods give similar results? Agriculture 62, 52-61. doi: 10.1515/agri-2016-0006 
Öztürk, A. I., Yilmaz, O., Kirbağ, S., and Arslan, M. (2000). Antimicrobial and biological effects of ipemphos and amphos on bacterial and yeast strains. Cell Biochem. Funct. 18, 117-126. doi: 10.1002/(SICI)1099-0844(200006)18 $: 2<117::$ AID-CBF863>3.0.CO;2-1

Paulose, J. K., Wright, J. M., Patel, A. G., and Cassone, V. M. (2016). Human gut bacteria are sensitive to melatonin and express endogenous circadian rhythmicity. PLoS One 11:e0146643. doi: 10.1371/journal.pone.0146643

Qadir, S., Jamshieed, S., Rasool, S., Ashraf, M., Akram, N. A., and Ahmad, P. (2014). "Modulation of plant growth and metabolism in cadmium-enriched environments" in Reviews of Environmental Contamination and Toxicology. ed. D. M. Whitacre (Cham: Springer International Publishing), 229, 51-88. doi: 10.1007/978-3-319-03777-6_4

Rajapaksha, R. M. C. P., Tobor-Kapłon, M. A., and Bååth, E. (2004). Metal toxicity affects fungal and bacterial activities in soil differently. Appl. Environ. Microbiol. 70, 2966-2973. doi: 10.1128/AEM.70.5.2966-2973.2004

Ramette, A. (2009). Quantitative community fingerprinting methods for estimating the abundance of operational taxonomic units in natural microbial communities. Appl. Environ. Microbiol. 75, 2495-2505. doi: 10.1128/AEM.02409-08

Rath, K. M., Maheshwari, A., Bengtson, P., and Rousk, J. (2016). Comparative toxicities of salts on microbial processes in soil. Appl. Environ. Microbiol. 82, 2012-2020. doi: 10.1128/AEM.04052-15

Reese, A. T., Lulow, K., David, L. A., and Wright, J. P. (2018). Plant community and soil conditions individually affect soil microbial community assembly in experimental mesocosms. Ecol. Evol. 8, 1196-1205. doi: 10.1002/ece3.3734

Reiter, R. J., Mayo, J. C., Tan, D. X., Sainz, R. M., Alatorre-Jimenez, M., and Qin, L. (2016). Melatonin as an antioxidant: under promises but over delivers. J. Pineal Res. 61, 253-278. doi: 10.1111/jpi.12360

Reiter, R. J., Tan, D. X., Zhou, Z., Cruz, M. H. C., Fuentes-Broto, L., and Galano, A. (2015). Phytomelatonin: assisting plants to survive and thrive. Molecules 20, 7396-7437. doi: 10.3390/molecules20047396

Rincon-Florez, V. A., Carvalhais, L. C., and Schenk, P. M. (2013). Cultureindependent molecular tools for soil and rhizosphere microbiology. Diversity 5, 581-612. doi: 10.3390/d5030581

Roberts, T. L. (2014). Cadmium and phosphorous fertilizers: the issues and the science. Procedia Eng. 83, 52-59. doi: 10.1016/j.proeng.2014.09.012

Rodriguez, C., Mayo, J. C., Sainz, R. M., Antolín, I., Herrera, F., Martín, V., et al. (2004). Regulation of antioxidant enzymes: a significant role for melatonin. J. Pineal Res. 36, 1-9. doi: 10.1046/j.1600-079X.2003.00092.x

Rodriguez-Naranjo, M. I., Torija, M. J., Mas, A., Cantos-Villar, E., and GarciaParrilla, M. D. C. (2012). Production of melatonin by Saccharomyces strains under growth and fermentation conditions. J. Pineal Res. 53, 219-224. doi: 10.1111/j.1600-079X.2012.00990.x

Schultz, C. L., Edrington, T. S., Callaway, T. R., Schroeder, S. B., Hallford, D. M., Genovese, K. J., et al. (2006). The influence of melatonin on growth of E. coli O157:H7 in pure culture and exogenous melatonin on faecal shedding of $E$. coli O157:H7 in experimentally infected wethers. Lett. Appl. Microbiol. 43, 105-110. doi: 10.1111/j.1472-765X.2006.01909.x

Shao, H., Chu, L., Lu, H., Qi, W., Chen, X., Liu, J., et al. (2019). Towards sustainable agriculture for the salt-affected soil. Land Degrad. Dev. 30, 574-579. doi: 10.1002/ldr.3218

Sharif, R., Xie, C., Zhang, H., Arnao, M. B., Ali, M., Ali, Q., et al. (2018). Melatonin and its effects on plant systems. Molecules 23:2352. doi: 10.3390/ molecules 23092352

Sørensen, J., Nicolaisen, M. H., Ron, E., and Simonet, P. (2009). Molecular tools in rhizosphere microbiology-from single-cell to whole-community analysis. Plant Soil 321, 483-512. doi: 10.1007/s11104-009-9946-8

Spaepen, S., and Vanderleyden, J. (2011). Auxin and plant-microbe interactions. Cold Spring Harb. Perspect. Biol. 3. doi: 10.1101/cshperspect.a001438

Tan, D. X., Hardeland, R., Manchester, L. C., Korkmaz, A., Ma, S., RosalesCorral, S., et al. (2012). Functional roles of melatonin in plants, and perspectives in nutritional and agricultural science. J. Exp. Bot. 63, 577-597. doi: $10.1093 / \mathrm{jxb} / \mathrm{err} 256$

Tan, D. X., Zheng, X. D., Kong, J., Manchester, L. C., Hardeland, R., Kim, S. J., et al. (2014). Fundamental issues related to the origin of melatonin and melatonin isomers during evolution: relation to their biological functions. Int. J. Mol. Sci. 15, 15858-15890. doi: 10.3390/ijms150915858

Tanaka, T., Nishio, K., Usuki, Y., and Fujita, K. I. (2006). Involvement of oxidative stress induction in $\mathrm{Na}^{+}$toxicity and its relation to the inhibition of a $\mathrm{Ca}^{2+}$-dependent but calcineurin-independent mechanism in Saccharomyces cerevisiae. J. Biosci. Bioeng. 101, 77-79. doi: 10.1263/jbb.101.77

Tekbas, O. F., Ogur, R., Korkmaz, A., Kilic, A., and Reiter, R. J. (2008). Melatonin as an antibiotic: new insights into the actions of this ubiquitous molecule. J. Pineal Res. 44, 222-226. doi: 10.1111/j.1600-079X.2007.00516.x

Thiem, D., Gołebiewski, M., Hulisz, P., Piernik, A., and Hrynkiewicz, K. (2018). How does salinity shape bacterial and fungal microbiomes of Alnus glutinosa roots? Front. Microbiol. 9:651. doi: 10.3389/fmicb.2018.00651

Van Wijngaarden, R. P. A., Van Den Brink, P. J., Oude Voshaar, J. H., and Leeuwangh, P. (1995). Ordination techniques for analysing response of biological communities to toxic stress in experimental ecosystems. Ecotoxicology 4, 61-77. doi: 10.1007/BF00350650

Wahid, F., Sharif, M., Steinkellner, S., Khan, M. A., Marwat, K. B., and Khan, S. A. (2016). Inoculation of arbuscular mycorrhizal fungi and phosphate solubilizing bacteria in the presence of rock phosphate improves phosphorus uptake and growth of maize. Pak. J. Bot. 48, 739-747.

Wall, D. H., and Virginia, R. A. (1999). Controls on soil biodiversity: insights from extreme environments. Appl. Soil Ecol. 13, 137-150. doi: 10.1016/ S0929-1393(99)00029-3

Wang, P., Chen, H., Kopittke, P. M., and Zhao, F. J. (2019). Cadmium contamination in agricultural soils of China and the impact on food safety. Environ. Pollut. 249, 1038-1048. doi: 10.1016/j.envpol.2019.03.063

Wang, H. X., Liu, F., and Ng, T. B. (2001). Examination of pineal indoles and 6-methoxy-2-benzoxazolinone for antioxidant and antimicrobial effects. Comp. Biochem. Physiol., Part C: Toxicol. Pharmacol. 130, 379-388. doi: 10.1016/ S1532-0456(01)00264-2

Wang, Y., Reiter, R. J., and Chan, Z. (2018). Phytomelatonin: a universal abiotic stress regulator. J. Exp. Bot. 69, 963-974. doi: 10.1093/jxb/erx473

Wang, P., Sun, X., Wang, N., Tan, D. X., and Ma, F. (2015). Melatonin enhances the occurrence of autophagy induced by oxidative stress in Arabidopsis seedlings. J. Pineal Res. 58, 479-489. doi: 10.1111/jpi.12233

Weeda, S., Zhang, N., Zhao, X. L., Ndip, G., Guo, Y. D., Buck, G. A., et al. (2014). Arabidopsis transcriptome analysis reveals key roles of melatonin in plant defense systems. PLoS One 9:e93462. doi: 10.1371/journal.pone.0093462

Wei, W., Li, Q. T., Chu, Y. N., Reiter, R. J., Yu, X. M., Zhu, D. H., et al. (2015). Melatonin enhances plant growth and abiotic stress tolerance in soybean plants. J. Exp. Bot. 66, 695-707. doi: 10.1093/jxb/eru392

Wood, J. L., Tang, C., and Franks, A. E. (2016a). Microbial associated plant growth and heavy metal accumulation to improve phytoextraction of contaminated soils. Soil Biol. Biochem. 103, 131-137. doi: 10.1016/j.soilbio.2016.08.021

Wood, J. L., Zhang, C., Mathews, E. R., Tang, C., and Franks, A. E. (2016b). Microbial community dynamics in the rhizosphere of a cadmium hyperaccumulator. Sci. Rep. 6, 1-10. doi: 10.1038/srep36067

Yan, N., Marschner, P., Cao, W., Zuo, C., and Qin, W. (2015). Influence of salinity and water content on soil microorganisms. Int. Soil Water Conserv. Res. 3, 316-323. doi: 10.1016/j.iswcr.2015.11.003

Yao, H., He, Z., Wilson, M. J., and Campbell, C. D. (2000). Microbial biomass and community structure in a sequence of soils with increasing fertility and changing land use. Microb. Ecol. 40, 223-237. doi: 10.1007/s002480000053

Zancarini, A., Mougel, C., Voisin, A. S., Prudent, M., Salon, C., and MunierJolain, N. (2012). Soil nitrogen availability and plant genotype modify the nutrition strategies of $M$. truncatula and the associated rhizosphere microbial communities. PLoS One 7:e47096. doi: 10.1371/journal.pone.0047096

Zhan, H., Nie, X., Zhang, T., Li, S., Wang, X., Du, X., et al. (2019). Melatonin: a small molecule but important for salt stress tolerance in plants. Int. J. Mol. Sci. 20:709. doi: 10.3390/ijms20030709

Zhang, Q., Jin, H., Zhou, H., Cai, M., Li, Y., Zhang, G., et al. (2019). Variation of soil anaerobic microorganisms connected with anammox processes by 13C-phospholipid fatty acid analysis among long-term fertilization regimes in a crop rotation system. Appl. Soil Ecol. 133, 34-43. doi: 10.1016/j.apsoil.2018.09.005

Zhang, N., Sun, Q., Zhang, H., Cao, Y., Weeda, S., Ren, S., et al. (2015). Roles of melatonin in abiotic stress resistance in plants. J. Exp. Bot. 66, 647-656. doi: 10.1093/jxb/eru336

Zhang, Y. P., Yang, S. J., and Chen, Y. Y. (2017a). Effects of melatonin on photosynthetic performance and antioxidants in melon during cold and recovery. Biol. Plant. 61, 571-578. doi: 10.1007/s10535-017-0717-8

Zhang, N., Zhang, H. J., Sun, Q. Q., Cao, Y. Y., Li, X., Zhao, B., et al. (2017b). Proteomic analysis reveals a role of melatonin in promoting cucumber seed 
germination under high salinity by regulating energy production. Sci. Rep. 7:503. doi: 10.1038/s41598-017-00566-1

Zhao, J., Ni, T., Li, Y., Xiong, W., Ran, W., Shen, B., et al. (2014). Responses of bacterial communities in arable soils in a rice-wheat cropping system to different fertilizer regimes and sampling times. PLoS One 9:e85301. doi: 10.1371/journal.pone.0085301

Zhong, W. H., and Cai, Z. C. (2007). Long-term effects of inorganic fertilizers on microbial biomass and community functional diversity in a paddy soil derived from quaternary red clay. Appl. Soil Ecol. 36, 84-91. doi: 10.1016/j. apsoil.2006.12.001
Conflict of Interest: The authors declare that the research was conducted in the absence of any commercial or financial relationships that could be construed as a potential conflict of interest.

Copyright (c) 2019 Madigan, Egidi, Bedon, Franks and Plummer. This is an open-access article distributed under the terms of the Creative Commons Attribution License (CC $B Y)$. The use, distribution or reproduction in other forums is permitted, provided the original author(s) and the copyright owner(s) are credited and that the original publication in this journal is cited, in accordance with accepted academic practice. No use, distribution or reproduction is permitted which does not comply with these terms. 